\title{
MED1 is a lipogenesis coactivator required for postnatal adipose expansion
}

\author{
Younghoon Jang, ${ }^{1,2,4}$ Young-Kwon Park, ${ }^{1,4}$ Ji-Eun Lee, ${ }^{1}$ Danyang Wan, ${ }^{1}$ Nhien Tran, ${ }^{1}$ \\ Oksana Gavrilova, ${ }^{3}$ and $\mathrm{Kai}_{\mathrm{Ge}}{ }^{1}$ \\ ${ }^{1}$ Adipocyte Biology and Gene Regulation Section, National Institute of Diabetes and Digestive and Kidney Diseases, National \\ Institutes of Health, Bethesda, Maryland 20892, USA; ${ }^{2}$ Department of Biology and Chemistry, Changwon National University, \\ Changwon 51140, Korea; ${ }^{3}$ Mouse Metabolism Core, National Institute of Diabetes and Digestive and Kidney Diseases, National \\ Institutes of Health, Bethesda, Maryland 20892, USA
}

MED1 often serves as a surrogate of the general transcription coactivator complex Mediator for identifying active enhancers. MED1 is required for phenotypic conversion of fibroblasts to adipocytes in vitro, but its role in adipose development and expansion in vivo has not been reported. Here, we show that MED1 is not generally required for transcription during adipogenesis in culture and that MED1 is dispensable for adipose development in mice. Instead, MED1 is required for postnatal adipose expansion and the induction of fatty acid and triglyceride synthesis genes after pups switch diet from high-fat maternal milk to carbohydrate-based chow. During adipogenesis, MED1 is dispensable for induction of lineage-determining transcription factors (TFs) PPAR $\gamma$ and C/EBPa but is required for lipid accumulation in the late phase of differentiation. Mechanistically, MED1 controls the induction of lipogenesis genes by facilitating lipogenic TF ChREBP- and SREBP1a-dependent recruitment of Mediator to active enhancers. Together, our findings identify a cell- and gene-specific regulatory role of MED1 as a lipogenesis coactivator required for postnatal adipose expansion.

[Keywords: MED1; Mediator; adipose expansion; coactivator; de novo lipogenesis]

Supplemental material is available for this article.

Received November 30, 2020; revised version accepted March 16, 2021.

Adipose tissue development starts before birth. After birth, adipose tissues, especially white adipose tissue (WAT), undergo marked expansion with tissue mass and lipid contents increasing from newborn pups to adult mice (Cristancho and Lazar 2011; Berry et al. 2013). Adipose tissue development requires the master adipogenic transcription factor (TF) PPAR $\gamma$, which is induced in the early phase of adipogenesis, the differentiation of preadipocytes towards adipocytes (Rosen et al. 2002). PPAR $\gamma$ cooperates with $\mathrm{C} / \mathrm{EBP} \alpha$ on transcriptional enhancers to induce the expression of thousands of adipocyte genes that also include major lipogenic TFs ChREBP and SREBP1, which together promote de novo lipogenesis (DNL) in the late phase of adipogenesis (Lefterova et al. 2008; Schmidt et al. 2011).

Liver and adipose tissues are the main sites for DNL in mammals. Fatty acid synthesis is low in liver and adipose tissue of mouse pups but increases dramatically after the switch of diet from high-fat maternal milk to carbohydrate-rich standard laboratory chow (Pearce 1983). DNL is a tightly regulated metabolic process that converts ex-

\footnotetext{
${ }^{4}$ These authors contributed equally to this work. Corresponding author: kai.ge@nih.gov

Article published online ahead of print. Article and publication date are online at http://www.genesdev.org/cgi/doi/10.1101/gad.347583.120. Freely available online through the Genes \& Development Open Access option.
}

cess carbohydrates to fatty acids before the synthesis of triglyceride for energy storage. Through glycolysis and the tricarboxylic acid cycle, carbohydrates are converted to citrate. Fatty acid synthesis enzymes, including ATP citrate lyase (ACLY), acetyl-CoA carboxylase $\alpha / \beta$ (ACACA/ ACACB, also known as ACC1/ACC2), fatty acid synthase (FASN), and stearoyl-CoA desaturase-1/2/3/4 (SCD1/2/3/ 4 ), act sequentially to convert citrate to fatty acids (Strable and Ntambi 2010; Song et al. 2018). Through the subsequent actions of triglyceride synthesis enzymes GPAM (also known as GPAT1), 1-acylglycerol-3-phosphate O-acyltransferase-1/2 (AGPAT1/2), LIPIN1, and DGAT1, fatty acids are esterified with glycerol-3-phosphate and incorporated into triglyceride (Takeuchi and Reue 2009).

DNL enzyme expression is transcriptionally regulated by major lipogenic TFs carbohydrate-responsive element-binding protein (ChREBP, also known as MLXIPL) and sterol regulatory element-binding protein 1 (SREBP1) in adipose tissues. ChREBP is a major driver for adipocyte DNL (Song et al. 2018). It is expressed as two isoforms ChREBP $\alpha$ and ChREBP $\beta$, which are encoded by the same gene but transcribed from different promoters. ChREBP $\beta$ transcription activity is $\sim 20$-fold higher than that of

This is a work of the US Government. 
ChREBPa (Herman et al. 2012). ChREBPa is constitutively expressed but is sequestered in the cytosol and transcriptionally inactive under low glucose conditions. ChREBPa is activated by high glucose and, in turn, stimulates ChREBP $\beta$ expression (Abdul-Wahed et al. 2017). Overexpression of the constitutively active form of ChREBP (CA-ChREBP) in mouse WAT induces expression of DNL enzymes such as ACLY, ACACA, FASN, and SCD1 (Nuotio-Antar et al. 2015). ChIP-seq analysis in mouse WAT showed genomic binding of ChREBP on Acaca, Acacb, Fasn, and Chrebp genes, suggesting that ChREBP directly regulates transcription of DNL enzymes as well as itself (Poungvarin et al. 2015). SREBP1 also promotes DNL gene expression in adipocytes. Overexpression of the SREBP1a isoform in adipose tissue increases the expression of fatty acid synthesis genes, leading to increased lipid accumulation in adipocytes (Horton et al. 2003).

In eukaryotes, all transcription is mediated by RNA polymerase II (Pol II) for protein-coding genes. Transcription by Pol II requires transcriptional coregulators including chromatin remodelers, histone modifiers, and the Mediator coactivator complex (Malik and Roeder 2010). The Mediator complex comprises approximately 30 subunits, and it generally serves as a functional bridge between TFs and basal transcriptional machinery including Pol II (Allen and Taatjes 2015). Mediator is enriched at transcriptional promoters and enhancers. One of the Mediator subunits, MED1 (also known as TRAP220, PBP), is often used as a surrogate for the Mediator to identify active enhancers and superenhancers (Whyte et al. 2013). Wholebody Med1 KO in mice leads to embryonic lethality around E11.5 (Ito et al. 2000; Zhu et al. 2000).

We previously reported that Med1 KO mouse embryonic fibroblasts show defects in PPAR $\gamma$ - and C/EBP $\beta$-stimulated phenotypic conversion into adipocytes (Ge et al. 2002, 2008). However, it has remained unclear whether MED1 is required for adipose tissue development and expansion in vivo. Using Adipoq-Cre- or Myf5-Cre-mediated deletion of Med1 in adipocytes or precursor cells in mice, we show that MED1 is required for postnatal adipose expansion after switching diet from high-fat maternal milk to carbohydrate-based standard chow and that MED1 is largely dispensable for adipose tissue development. By RNA-seq and ChIP-seq analyses, we found that MED1 does not control the expression of early adipogenesis marker Pparg but directly controls the transcription of lipogenesis genes that encode fatty acid synthesis enzymes ACLY, ACACA, SCD1, and FASN and triglyceride synthesis enzymes GPAM and AGPAT2 in adipocytes. Mechanistically, MED1 facilitates Mediator binding on active enhancers of ChREBP- and SREBPla-regulated lipogenesis genes in adipocytes.

\section{Results}

Med1 ${ }^{f / f}$;Adipoq-Cre mice show lipodystrophy and fail to expand adipose tissue under high-fat diet

To investigate the functional role of MED1 in adipose tissues, we used conditional knockout (KO) mice targeting exons 8-10 of Med1 gene $\left(M e d 1^{\mathrm{f} / \mathrm{f}}\right.$, hereafter referred to as $\mathrm{f} / \mathrm{f}$ ) (Supplemental Fig. S1A; Jia et al. 2004). Adipocyte-specific Med1 KO (Med1 ${ }^{\mathrm{f} / \mathrm{f}}$;Adipoq-Cre [A-KO]) mice were generated by crossing f/f mice with AdipoqCre mice expressing Adiponectin promoter-driven Cre (Eguchi et al. 2011). A-KO mice showed similar appearance and total body weight compared with $\mathrm{f} / \mathrm{f}$ mice but had significantly reduced fat mass and increased lean mass at 8 wk (Fig. 1A,B). Adipose tissues including brown adipose tissue (BAT), inguinal WAT (iWAT), and epididymal WAT (eWAT) decreased in A-KO mice, while liver mass increased (Fig. 1C,D). Similar results were obtained from female mice at $8 \mathrm{wk}$ (Supplemental Fig. S1B-E). Histological analysis revealed reduced lipid droplets in adipose tissues of A-KO mice (Fig. 1E). Deletion of Med1 was verified in adipose tissues (Fig. 1F). These results indicate that deletion of Med1 in adipocytes leads to lipodystrophy in adult mice.

Blood glucose and insulin levels increased in the serum of A-KO mice, while leptin levels decreased. Free fatty acid, triglyceride, and cholesterol levels were similar between A-KO and f/f mice (Fig. 1G). A glucose tolerance test (GTT) and insulin tolerance test (ITT) showed that A-KO mice were insulin-resistant (Fig. 1H-I). Deletion of Med1 in adipocytes did not affect food intake and total activity but caused a significant increase in total energy expenditure, which was likely due to the increased lean mass (Supplemental Fig. S1F). However, in contrast to $f / f$ mice, A-KO mice failed to increase energy expenditure and showed reduced lipolysis upon stimulation with CL316,243, a $\beta 3$ adrenergic receptor agonist (Fig. 1J,K). A-KO mice maintained core body temperature when housed at room temperature $\left(\sim 22^{\circ} \mathrm{C}\right)$, but their body temperature significantly dropped to $\sim 31^{\circ} \mathrm{C}$ after $3 \mathrm{~h}$ exposure to an ambient temperature of $6^{\circ} \mathrm{C}$ (Fig. 1L). Expression of thermogenesis genes Ucp 1 and Elov13 decreased in BAT of A-KO mice at room temperature and failed to induce after 3-h cold exposure, indicating thermogenesis defects in A-KO mice (Fig. 1M). These data indicate that adipocyteselective deletion of Med1 impairs glucose homeostasis and cold-induced thermogenesis in mice.

Under a high-fat diet (HFD), A-KO mice gained significantly less body weight and fat mass compared with $\mathrm{f} / \mathrm{f}$ mice, but more lean mass (Fig. 2A-C; Supplemental Fig. S2A,B). Med1 KO had little effect on food intake and energy expenditure calculated by energy balance technique (Fig. 2D-E). After 8 wk of HFD, A-KO mice exhibited severe lipodystrophy phenotypes including dramatically reduced iWAT and eWAT mass, fatty liver, insulin resistance, hyperlipidemia, and reduced serum leptin levels (Fig. 2F-L; Supplemental Fig. S2C-E). These data indicate that mice with adipocyte-selective deletion of Med1 fail to expand adipose tissue under a HFD.

\section{MED1 is dispensable for embryonic development of BAT}

To find out whether MED1 is required for adipose tissue development, we used Myf5-Cre mice to delete Med1 in precursor cells of BAT and skeletal muscle (Tallquist et al. 2000). Med1 ${ }^{\mathrm{f} / \mathrm{f}}{ }_{;} M y f 5-C r e$ (M-KO) embryos were 


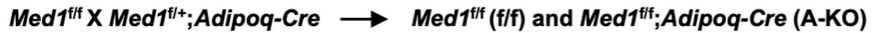

A Male, 8 wk

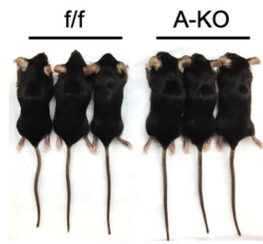

D

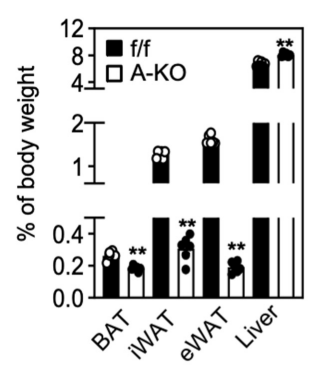

B

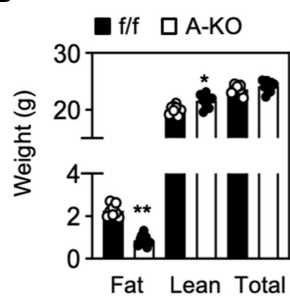

E

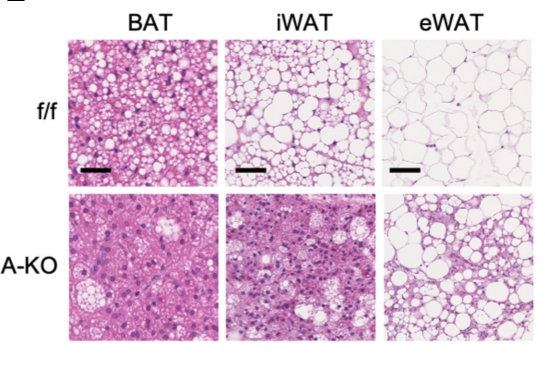

C

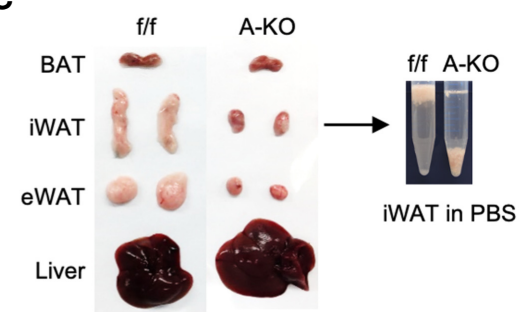

F qRT-PCR

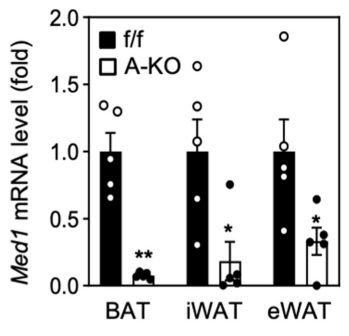

G Serum metabolites
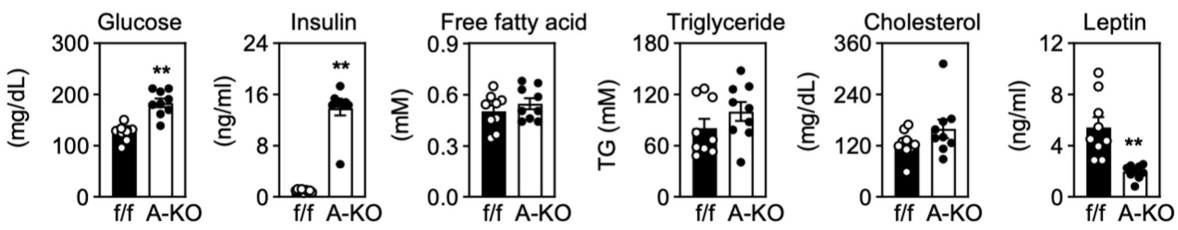

H GTT

I ITT
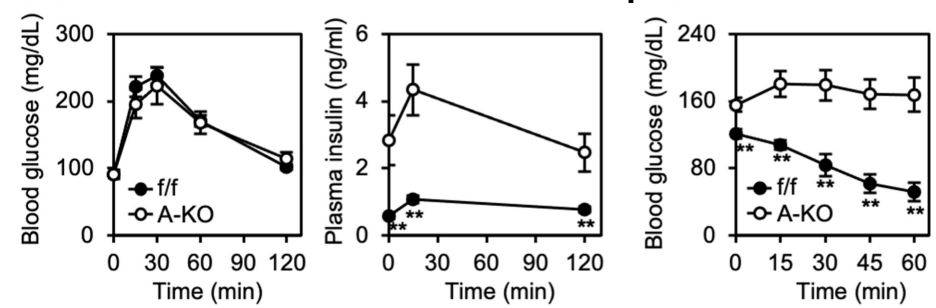

$\mathbf{J}$

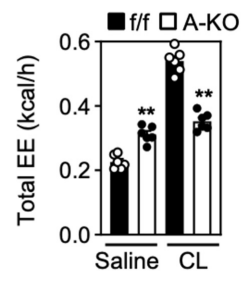

K Lipolysis

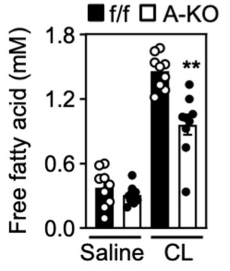

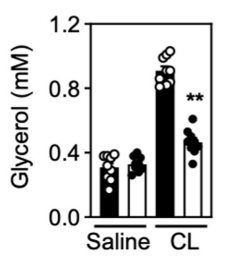

L Cold tolerance

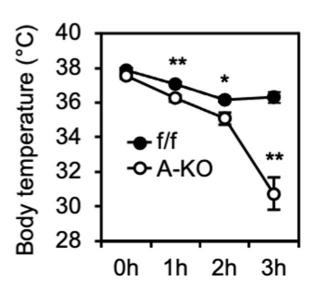

M qRT-PCR: BAT

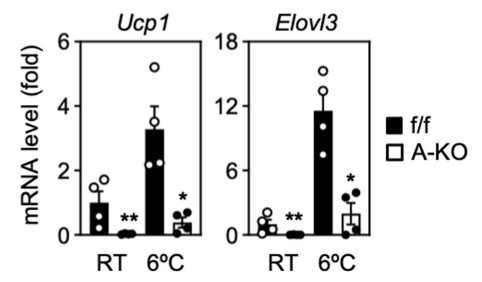

Figure 1. Deletion of Med1 in adipocytes leads to lipodystrophy. $(A-F)$ All data were from 8-wk male mice fed with a regular diet. $(A)$ Representative morphology of adult mice. $(B)$ Body composition measured by MRI ( $n=8$ per group). $(C)$ Representative pictures of BAT, iWAT, eWAT, and liver. iWAT from A-KO mice failed to float in PBS. (D) Average tissue weights are presented as percentage of body weight ( $n=6$ per group). (E) H\&E staining shows reduced lipid droplet in A-KO adipose tissues. Scale bar, $100 \mu \mathrm{m}$. $(F)$ qRT-PCR analysis of Med1 mRNA levels ( $n=5$ per group). (G) Levels of serum metabolites ( $n=8$ per group). (H) Glucose tolerance test (GTT) (left panel) and plasma insulin levels (right panel) ( $n=8$ per group). (I) Insulin tolerance test (ITT). Absolute blood glucose levels are shown. (J) Total energy expenditure (EE) after saline or CL316,243 (CL) administration. $(K)$ Lipolysis analysis. Serum levels of free fatty acid or glycerol were measured after saline or CL administration. $(L, M)$ Cold tolerance test. $(L)$ Body temperatures $(n=6$ per group). (M) qRT-PCR of $U c p 1$ and Elov13 in BAT ( $n=4$ per group). All quantitative data for mice are presented as means \pm SEM. Statistical comparison between groups was performed using Student's $t$-test. $\left(^{*}\right) P<0.05,\left({ }^{* *}\right) P<0.01$. 


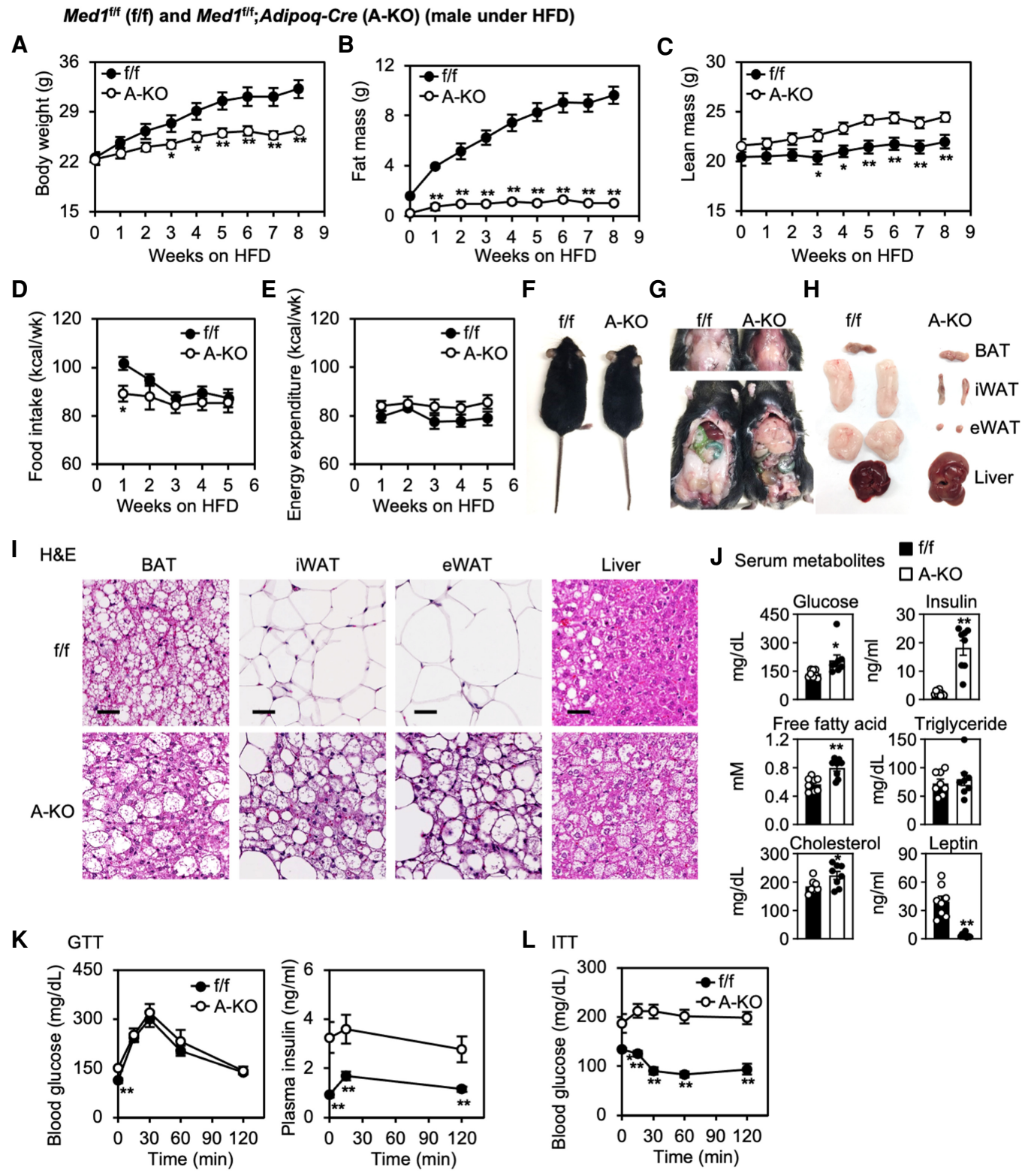

Figure 2. Mice with adipocyte-selective deletion of $M e d 1$ fail to expand adipose tissue under high-fat diet. Male $\mathrm{f} / \mathrm{f}$ and A-KO mice $(n=8$ per group) were fed with a high-fat diet (HFD) from the eighth week of age. Data for female mice are shown in Supplemental Figure S2. $(A-C)$ Total body weight $(A)$, fat mass $(B)$, and lean mass $(C)$ were measured by MRI during HFD feeding. $(D, E)$ Food intake $(D)$ and total energy expenditure $(E)$. $(F)$ Representative morphology of HFD-fed mice. $(G)$ Representative pictures of the interscapular area (upper area) and abdominal area (lower panel) after 8 wk of HFD feeding. $(H)$ Representative pictures of each fat depot and liver. $(I)$ H\&E staining of each fat depot and liver. Scale bar, $100 \mu \mathrm{m}$. (J) Levels of serum metabolites. (K) GTT (left panel) and plasma insulin levels (right panel). $(L)$ ITT. Absolute blood glucose levels are shown. Statistical comparison between groups was performed using Student's $t$-test. $\left(^{*}\right) P<0.05$, $(* *) P<0.01$.

obtained at the expected ratio without showing morphological differences compared with $\mathrm{f} / \mathrm{f}$ embryos (Fig. 3A, B). M-KO embryos did not show observable differences in BAT mass compared with $\mathrm{f} / \mathrm{f}$ embryos (Fig. $3 \mathrm{C}, \mathrm{D}$ ). In addition, Myf5-Cre-mediated deletion of Med1 had little effect on the expression of adipogenesis markers Pparg, Cebpa, and Fabp4 but significantly reduced brown adipocyte marker Ucp1 expression (Fig. 3E). Decreased Ucp1 expression in Med1 KO BAT is consistent with previous observations that MED1 is required for Ucp1 expression in brown adipocytes in culture (Harms et al. 2015; Iida et al. 2015). Although M-KO mice had largely intact BAT and muscle before birth, they became runts and showed severe growth retardation and reduced survival rates around 3-4 wk after birth, possibly due to muscle development defects (Fig. 3A; Supplemental Fig. S3). These data suggest that MED1 is largely dispensable for embryonic development of BAT. 


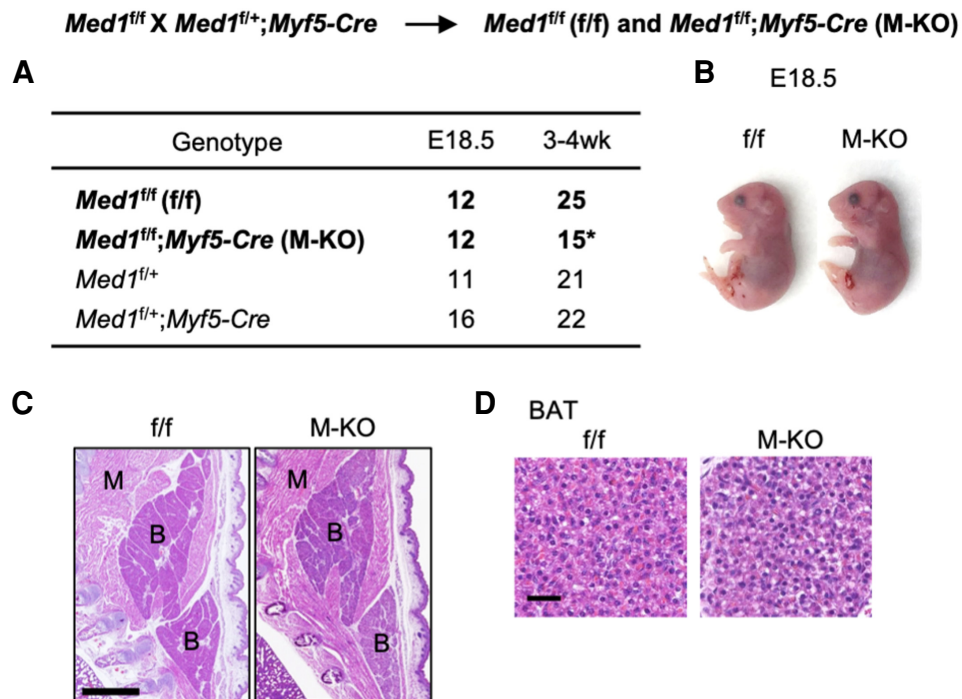

E $\quad$ QRT-PCR

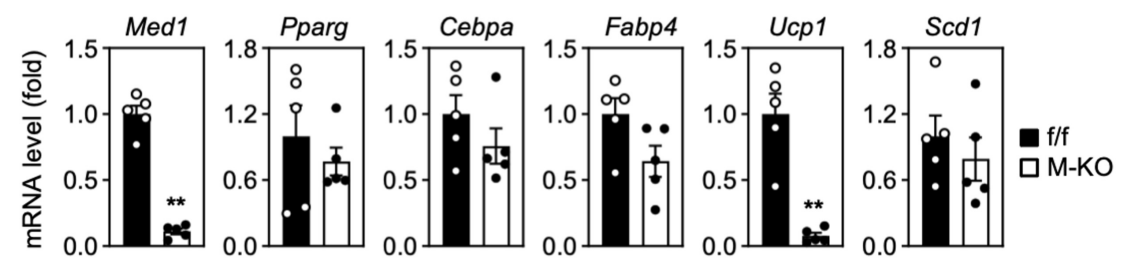

Figure 3. MED1 is dispensable for embryonic development of BAT. $(A-E) \operatorname{Med} 1^{\mathrm{f} / \mathrm{f}}$; Myf5-Cre (M-KO) mice show largely intact BAT before birth. Med1/f/f $(\mathrm{f} / \mathrm{f})$ mice were crossed with Myf5-Cre to generate M-KO mice. (A) Genotypes of mice at E18.5 and 3-4 wk. The expected ratio of the four genotypes is 1:1:1:1. Numbers of $\mathrm{M}-\mathrm{KO}$ mice at 3-4 wk were reduced as indicated by an asterisk. Data from 3- to 4-wk M-KO mice are shown in Supplemental Figure S3. $(B)$ Representative morphology of E18.5 embryos. (C) H\&E staining of E18.5 embryos. Sagittal sections of the cervical/thoracic area are shown. Scale bar, $80 \mu \mathrm{m}$. (D) H\&E staining of BAT at E18.5. (E) qRT-PCR of Med1, Pparg, Cebpa, Fabp4, Ucp1, and Scd1 expression in BAT of E18.5 embryos $(n=5$ per group). Statistical comparison between groups was performed using Student's $t$ test. $\left.{ }^{* *}\right) P<0.01$.

\section{MED1 is required for postnatal adipose expansion and lipogenesis gene expression}

Since the requirement for MED1 to maintain adiposity was observed only after birth, we focused on postnatal adipose expansion in mice, which is stimulated by changes from breastfeeding to carbohydrate-rich diet (Fig. 4A; Pearce 1983). We sought to profile cell type-specific transcriptomes in adiponectin-positive $\left(\right.$ Adipo $\left.^{+}\right)$adipocytes during postnatal adipose expansion (Fig. 4B,C). For this purpose, we first crossed TRAP (Translating Ribosome Affinity Purification) mice (Zhou et al. 2013) with AdipoqCre mice to label ribosomes in Adipo ${ }^{+}$adipocytes. GFPtagged ribosomes were isolated from interscapular BAT and iWAT of newborn and adult mice for RNA-seq analyses (Fig. 4D). Using a fivefold cutoff for differential gene expression, we identified genes that are induced $(1.6 \%, 214)$ $13,285)$ or reduced $(1.8 \%, 240 / 13,285)$ in Adipo $^{+}$brown adipocytes from postnatal day 0.5 (P0.5) to $12 \mathrm{wk}$ (Fig. $4 \mathrm{E})$. Induced genes were functionally associated with lipogenesis but not adipogenesis (Fig. 4F). Lipogenesis genes including Acly, Acaca, Fasn, and Scd1, which encode four key fatty acid synthesis enzymes, were markedly induced in brown adipocytes from newborn to adult mice (Fig. 4G). Similarly, we identified induced $(4.0 \%, 552 /$ $13,799)$ or reduced $(5.4 \%, 745 / 13,799)$ genes in Adipoq $^{+}$ white adipocytes from P2.5 to $12 \mathrm{wk}$ (Fig. 4H). Four key lipogenesis enzyme genes, Acly, Acaca, Fasn, and Scd1, were induced over fivefold in white adipocytes from P2.5 to $12 \mathrm{wk}$ (Fig. 4G-I). Western blot analyses confirmed that protein levels of SCD1 and FASN were highly induced during postnatal expansion of BAT and iWAT but not those of adipogenesis markers and master regulators PPAR $\gamma$ and C/EBPa (Fig. 4J). These results indicate that postnatal adipose expansion is associated with marked induction of lipogenesis enzymes in adipocytes from newborn to adult mice.

To investigate the role of MED1 in postnatal adipose expansion, we isolated fat depots from $\mathrm{f} / \mathrm{f}$ and $\mathrm{A}-\mathrm{KO}$ mice at breastfeeding stage (P10) and carbohydrate-rich diet feeding stages ( $4 \mathrm{wk}$ and $8 \mathrm{wk}$ ). We did not observe any discernible differences in total body weight and interscapular WAT between $\mathrm{f} / \mathrm{f}$ and A-KO mice at P10 (Fig. 5A; Supplemental Fig. S4). However, A-KO mice exhibited nearly complete loss of interscapular WAT as well as reduced BAT and iWAT mass at 4 wk and $8 \mathrm{wk}$ (Fig. 5B,C; Supplemental Fig. S4). These results suggest that MED1 is required for adipose expansion during carbohydrate-rich diet feeding stages but not during breastfeeding. RNAseq analysis showed that Adipoq-Cre-mediated deletion of Med1 did not affect the expression of adipogenesis marker Pparg but impaired the induction of lipogenesis genes including fatty acid synthesis enzyme genes Acly, Acaca, Acacb, Fasn, and Scd1, triglyceride synthesis enzyme genes Gpam and Agpat2, and lipid uptake genes Fatty acid transport 1 (Fatp1) and Fatp2 from P10 to 4 wk and $8 \mathrm{wk}$ in both BAT and iWAT (Fig. 5D-F). Together, these data indicate that MED1 is required for postnatal adipose expansion and lipogenesis gene expression when mice switch from breastfeeding to a carbohydrate-rich diet. 
A

Postnatal adipose expansion

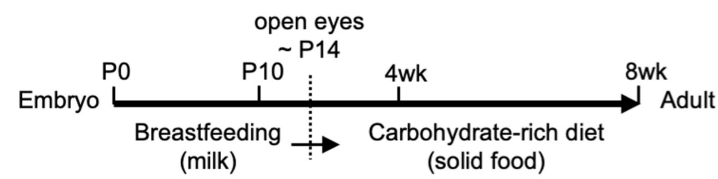

TRAP;Adipoq-Cre $\longrightarrow$ Adipoq $^{+}$adipocytes $\longrightarrow$ RNA-Seq

D
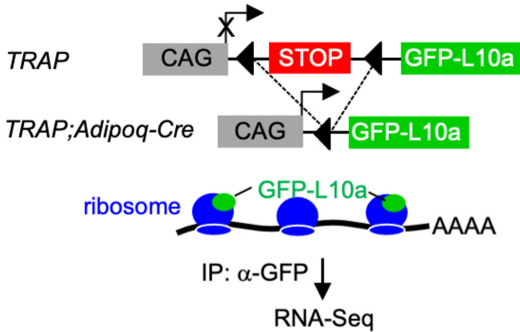

G TRAP: RNA-Seq (RPKM)

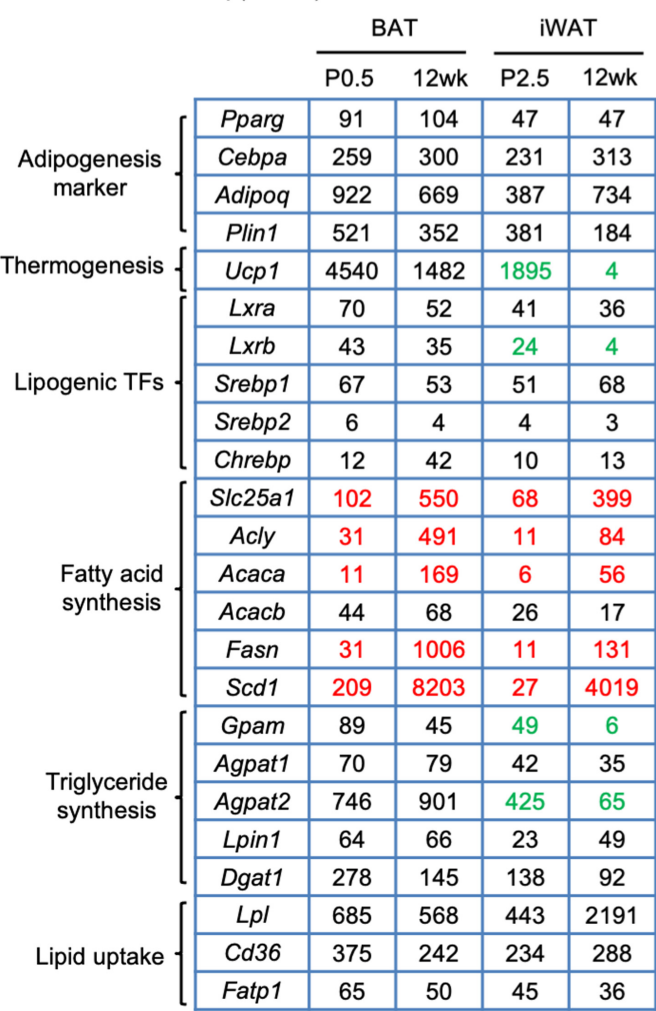

B

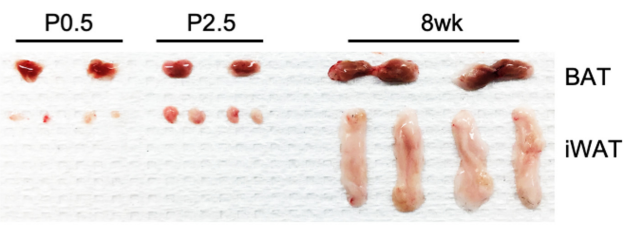

C H\&E

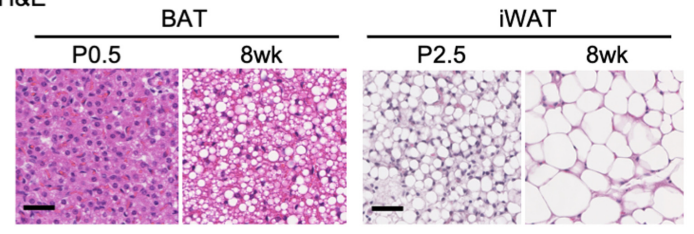

E TRAP RNA-Seq (BAT) F

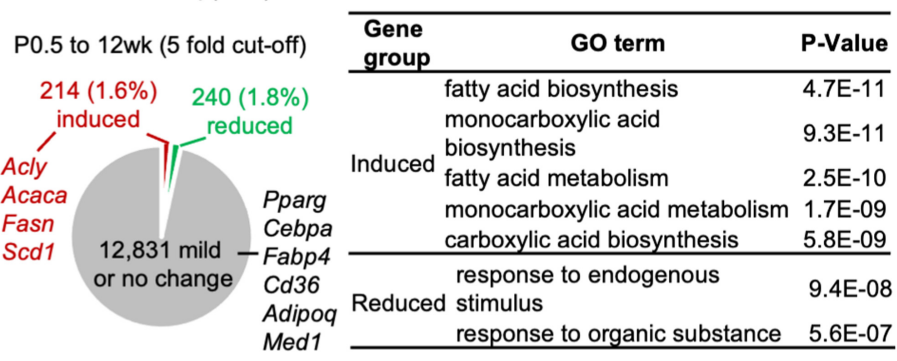

H TRAP RNA-Seq (IWAT) I

P2.5 to 12 wk (5 fold cut-off)

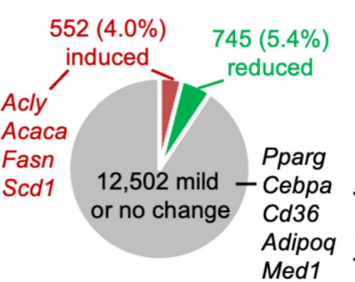

\begin{tabular}{ccc}
\hline $\begin{array}{c}\text { Gene } \\
\text { group }\end{array}$ & P-Value \\
\hline \multicolumn{2}{c}{ antigen processing and } \\
presentation & $4.1 \mathrm{E}-18$ \\
& defense response & $1.4 \mathrm{E}-11$ \\
Induced & response to organic substance & $3.3 \mathrm{E}-10$ \\
heat generation & $4.9 \mathrm{E}-09$ \\
& $8.9 \mathrm{E}-09$ \\
lipid metabolism & $1.1 \mathrm{E}-08$ \\
\hline lipid biosynthesis & $7.0 \mathrm{E}-12$ \\
\hline \multirow{2}{*}{ Reduced coenzyme metabolism } & $1.5 \mathrm{E}-11$ \\
\hline
\end{tabular}

J Whole cell lysates

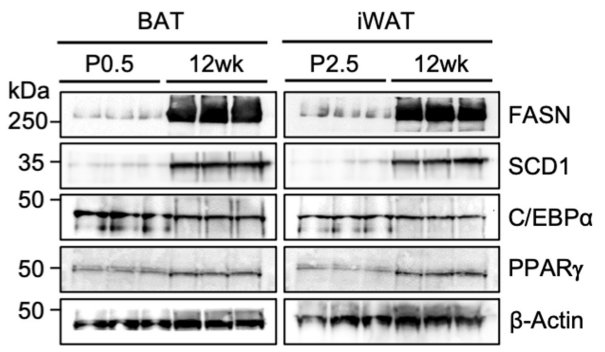

Figure 4. Marked induction of lipogenesis enzymes in adipocytes during postnatal adipose expansion. $(A-C)$ Increased adipose tissue size and lipid accumulation from newborn to adult mice. $(A)$ Schematics of postnatal development stages from newborn to adult mice. $(B)$ Representative pictures of BAT and iWAT of mice at postnatal day 0.5 (P0.5), P2.5, and 8 wk. Adipose tissues from two mice are shown. $(C)$ H\&E staining of BAT and iWAT. Scale bar, $80 \mu \mathrm{m}$. (D- $/$ ) Lipogenesis enzyme expression is highly induced during postnatal expansion of BAT and iWAT. (D) Schematics of experimental design. TRAP mice were crossed with Adipoq-Cre to delete the STOP signal and generate mice expressing GFP-fused L10a, an integral component of the 60S ribosomal subunit, in Adipoq ${ }^{+}$adipocytes. GFP-L10a-tagged ribosomes were immunoprecipitated with GFP antibody, and mRNA was purified for RNA-seq. (E,H) RNA-seq analysis of Adipoq ${ }^{+}$ adipocytes isolated from BAT $(E)$ or iWAT $(H)$ of TRAP;Adipoq-Cre mice at P0.5, P2.5, and $12 \mathrm{wk}$. The cutoff for induced or reduced genes from P0.5 or P2.5 to $12 \mathrm{wk}$ is fivefold. $(F, I)$ Gene ontology $(\mathrm{GO})$ analysis of gene groups defined in Eand $H$. (G) Expression levels of representative genes are shown in RPKM values of RNA-seq data from BAT and iWAT of TRAP;Adipoq-Cre mice. Gpam and Fatp1 are also known as Gpat1 and Slc27a1, respectively. (J) Western blot analysis of FASN, SCD1, C/EBPa, and PPAR $\gamma$ using whole-cell lysates from BAT (left panel) or iWAT (right panel). $\beta$-Actin was used as loading control. 
A

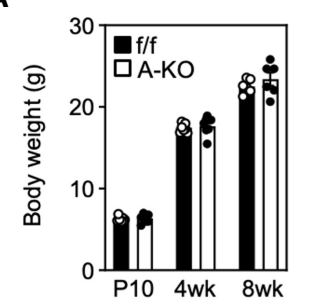

B

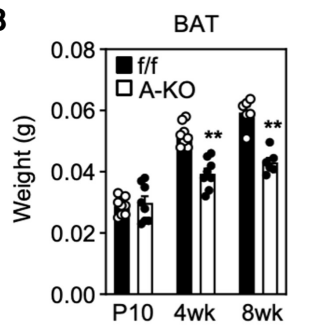

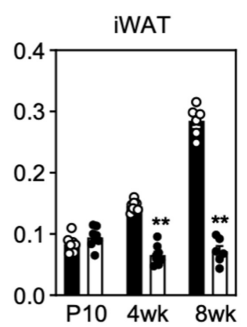

D RNA-Seq: down-regulated in A-KO (2.5 fold cut-off)

E

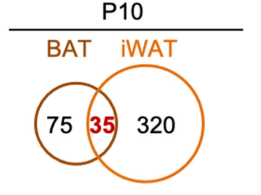

\begin{tabular}{ll}
\hline GO Term & P-value \\
\hline cellular response to interferon-beta & $8.50 \mathrm{E}-18$ \\
defense response to virus & $4.80 \mathrm{E}-12$ \\
immune system & $7.50 \mathrm{E}-09$ \\
innate immune response & $2.00 \mathrm{E}-07$ \\
cellular response to interferon-gamma & $4.70 \mathrm{E}-06$ \\
\hline
\end{tabular}

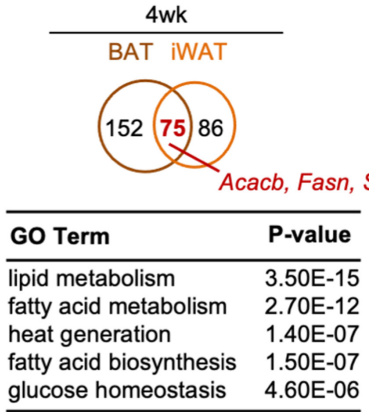

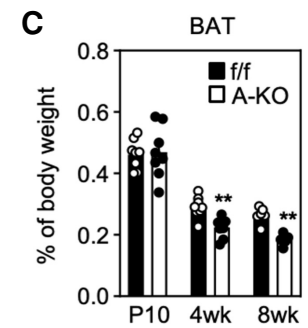

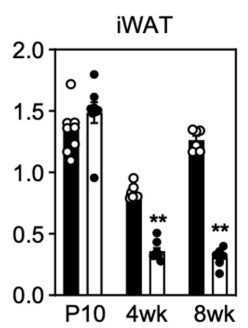

F RNA-Seq (RPKM)

Red: f/f vs A-KO > 2.5 fold

BAT

$\frac{P 10}{f / f \quad A-K O} \frac{4 w k}{f / f \quad A-K O} \frac{8 w k}{f / f \quad A-K O}$

\begin{tabular}{|c|c|c|c|c|c|c|c|}
\hline \multirow{4}{*}{$\begin{array}{l}\text { Adipogenesis } \\
\text { marker }\end{array}$} & Pparg & 83 & 70 & 87 & 52 & 50 & 40 \\
\hline & Cebpa & 178 & 143 & 279 & 98 & 192 & 70 \\
\hline & Adipoq & 300 & 378 & 411 & 558 & 435 & 636 \\
\hline & Plin1 & 256 & 256 & 373 & 148 & 237 & 135 \\
\hline
\end{tabular}

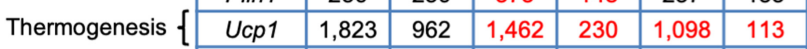

Lipogenic TFs

\begin{tabular}{|c|c|c|c|c|c|c|}
\hline Lxra & 23 & 32 & 21 & 36 & 20 & 28 \\
\hline Lxrb & 26 & 24 & 27 & 24 & 19 & 25 \\
\hline Srebp1 & 36 & 44 & 72 & 43 & 42 & 53 \\
\hline Srebp2 & 5 & 8 & 7 & 7 & 5 & 8 \\
\hline Chebp & 28 & 28 & 84 & 102 & 53 & 159 \\
\hline
\end{tabular}

\begin{tabular}{|c|c|c|c|c|c|c|c|}
\hline & Chrebp & 28 & 28 & 84 & 102 & 53 & 159 \\
\hline \multirow{6}{*}{$\begin{array}{l}\text { Fatty acid } \\
\text { synthesis }\end{array}$} & Acly & 26 & 47 & 1,049 & 540 & 313 & 293 \\
\hline & Acaca & 7 & 18 & 440 & 185 & 142 & 90 \\
\hline & $A c a c b$ & 53 & 23 & 170 & 50 & 104 & 35 \\
\hline & Fasn & 14 & 55 & 3,104 & 626 & 1,088 & 328 \\
\hline & Scd1 1 & 69 & 24 & 6,808 & 441 & 2,983 & 225 \\
\hline & Elovl6 & 20 & 20 & 138 & 74 & 65 & 48 \\
\hline \multirow{5}{*}{$\begin{array}{l}\text { Triglyceride } \\
\text { synthesis }\end{array}$} & Gpam & 42 & 27 & 61 & 20 & 21 & 8 \\
\hline & Agpat1 & 36 & 40 & 37 & 30 & 41 & 43 \\
\hline & Agpat2 & 221 & 188 & 743 & 122 & 336 & 74 \\
\hline & Lpin1 & 28 & 29 & 58 & 34 & 42 & 45 \\
\hline & Dgat1 & 95 & 109 & 93 & 96 & 71 & 78 \\
\hline \multirow{5}{*}{ Lipid uptake } & Lpl & 381 & 349 & 412 & 438 & 472 & 530 \\
\hline & Cd36 & 353 & 393 & 302 & 404 & 259 & 342 \\
\hline & Fatp1 & 54 & 42 & 62 & 37 & 40 & 31 \\
\hline & Fatp2 & 41 & 4 & 49 & 3 & 43 & 1.3 \\
\hline & Fatp4 & 6 & 7 & 8 & 7 & 5.4 & 6.1 \\
\hline
\end{tabular}

\begin{tabular}{|c|c|c|c|c|c|c|}
\hline & \multicolumn{6}{|c|}{ IWAT } \\
\hline & \multicolumn{2}{|c|}{$\mathrm{P} 10$} & \multicolumn{2}{|c|}{$4 \mathrm{wk}$} & \multicolumn{2}{|c|}{$8 w k$} \\
\hline & $f / f$ & A-KO & $f / f$ & A-KO & $f / f$ & A-KO \\
\hline Pparg & 47 & 48 & 71 & 47 & 18 & 13 \\
\hline Cebpa & 137 & 155 & 290 & 120 & 96 & 42 \\
\hline Adipoq & 734 & 754 & 997 & 972 & 448 & 512 \\
\hline Plin1 & 230 & 299 & 462 & 174 & 104 & 64 \\
\hline Ucp1 & 48 & 27 & 151 & 13 & 76 & 2 \\
\hline Lxra & 21 & 29 & 26 & 37 & 14 & 19 \\
\hline Lxrb & 25 & 29 & 27 & 30 & 17 & 24 \\
\hline Srebp1 & 32 & 46 & 89 & 41 & 35 & 34 \\
\hline Srebp2 & 11 & 16 & 12 & 13 & 11 & 23 \\
\hline Chrebp & 9 & 9 & 34 & 46 & 19 & 28 \\
\hline Acly & 20 & 36 & 720 & 297 & 163 & 96 \\
\hline Acaca & 7 & 9 & 329 & 97 & 71 & 26 \\
\hline Acacb & 8 & 4 & 60 & 15 & 27 & 8 \\
\hline Fasn & 28 & 42 & 2,015 & 372 & 387 & 100 \\
\hline Scd1 & 1,544 & 45 & 6,374 & 138 & 1,653 & 79 \\
\hline Elovl6 & 3 & 5 & 115 & 27 & 44 & 9 \\
\hline Gpam & 10 & 12 & 38 & 9 & 6 & 4 \\
\hline Agpat1 & 24 & 30 & 31 & 33 & 39 & 38 \\
\hline Agpat2 & 80 & 115 & 501 & 101 & 97 & 30 \\
\hline Lpin1 & 14 & 14 & 45 & 22 & 31 & 18 \\
\hline Dgat1 & 71 & 73 & 111 & 95 & 50 & 35 \\
\hline Lpl & 970 & 958 & 1,246 & 752 & 565 & 297 \\
\hline Cd36 & 399 & 548 & 516 & 515 & 145 & 151 \\
\hline Fatp1 & 108 & 48 & 164 & 45 & 62 & 18 \\
\hline Fatp2 & 1 & 0 & 4 & 0 & 2.5 & 0.1 \\
\hline Fatp4 & 6 & 11 & 9 & 8 & 4.4 & 5.4 \\
\hline
\end{tabular}

Figure 5. MED1 is required for postnatal adipose expansion and lipogenesis gene expression. $(A-C)$ MED1 is required for postnatal adipose expansion during carbohydrate-rich diet feeding stages. Total body weight $(A)$, average tissue weight $(B)$, and percentage of body weight $(C)$ are presented ( $n=8$ per group at $\mathrm{P} 10$ and $4 \mathrm{wk} ; n=6$ at $8 \mathrm{wk})$. Statistical comparison between groups was performed using Student's $t$-test. $\left({ }^{* *}\right) P<0.01 .(D-F)$ MED1 is required for lipogenesis gene expression during carbohydrate-rich diet feeding stages. BAT and iWAT were collected from $\mathrm{f} / \mathrm{f}$ and A-KO mice at P10, $4 \mathrm{wk}$, and $8 \mathrm{wk}$. Total RNA isolated from three to five mice per genotype was combined in equal amounts for RNA-seq. $(D)$ Numbers of down-regulated genes in adipose tissues of A-KO mice. The cutoff for differential expression is 2.5-fold. (E) GO analysis of down-regulated genes defined in $D$ in both BAT and iWAT of A-KO mice are shown. $(F)$ Expression levels of representative genes are shown in RPKM values. 
Immortalized $M$ Med1 ${ }^{\mathrm{fff}} ;$ Cre-ER brown preadipocytes

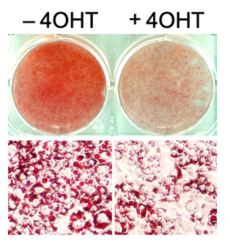

B RNA-Seq (D7, 2.5 fold cut-off)

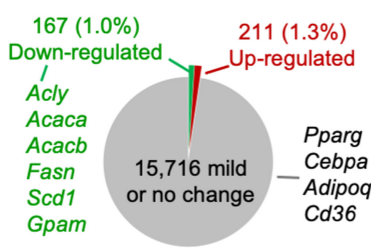

D7

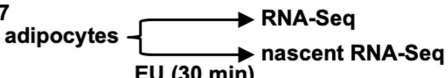

C

\begin{tabular}{|c|c|c|}
\hline $\begin{array}{l}\text { Gene } \\
\text { group }\end{array}$ & GO term & P-Value \\
\hline $\begin{array}{l}\text { Down- } \\
\text { regulated }\end{array}$ & $\begin{array}{l}\text { fatty acid biosynthesis } \\
\text { monocarboxylic acid biosynthesis } \\
\text { fat cell differentiation } \\
\text { carboxylic acid biosynthesis }\end{array}$ & $\begin{array}{l}3.3 \mathrm{E}-07 \\
1.9 \mathrm{E}-06 \\
7.2 \mathrm{E}-06 \\
1.7 \mathrm{E}-05\end{array}$ \\
\hline $\begin{array}{l}\text { Up- } \\
\text { regulated }\end{array}$ & $\begin{array}{l}\text { response to endogenous stimulus } \\
\text { organ morphogenesis } \\
\text { regulation of cell proliferation } \\
\text { cell adhesion }\end{array}$ & $\begin{array}{l}1.7 \mathrm{E}-07 \\
3.4 \mathrm{E}-07 \\
9.2 \mathrm{E}-07 \\
1.4 \mathrm{E}-06\end{array}$ \\
\hline
\end{tabular}

E

Nascent RNA-Seq (D7, 2 fold cut-off)

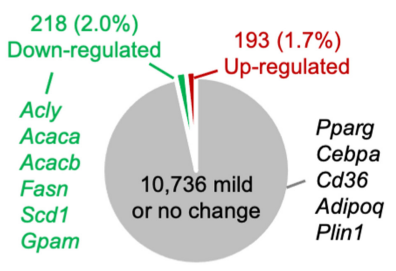

$\mathbf{F}$

\begin{tabular}{clc}
\hline $\begin{array}{c}\text { Gene } \\
\text { group }\end{array}$ & \multicolumn{1}{c}{ Go term } & P-Value \\
\hline & fatty acid biosynthesis & $2.8 \mathrm{E}-10$ \\
Down- & monocarboxylic acid biosynthesis & $4.4 \mathrm{E}-10$ \\
regulated & brown fat cell differentiation & $1.1 \mathrm{E}-09$ \\
& monocarboxylic acid metabolism & $2.8 \mathrm{E}-09$ \\
& fatty acid metabolism & $4.1 \mathrm{E}-09$ \\
\hline \multirow{3}{*}{ Up- $\quad$ locomotion } & $6.7 \mathrm{E}-12$ \\
regulated response to oxygen levels & $1.1 \mathrm{E}-09$ \\
$\quad$ localization of cell & $3.2 \mathrm{E}-09$ \\
\hline
\end{tabular}

H $\quad$ qRT-PCR (D7)

$$
\text { - }-4 \mathrm{OHT}
$$

$$
\square+4 \mathrm{OHT}
$$

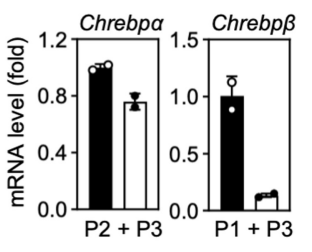

Figure 6. MED1 is required for lipogenesis but not early adipogenesis in culture. Immortalized $M e d 1^{\mathrm{f} / \mathrm{f}}$; $C r e-E R$ brown preadipocytes were treated with $4 \mathrm{OHT}$ to delete $M e d 1$, followed by adipogenesis assay, RNA-seq, or nascent RNA-seq. (A-C) MED1 is required for lipid accumulation and lipogenesis gene expression in culture. (A, left panel) Oil Red O staining at day 7 (D7) of adipogenesis is shown. (Right panel) Lipid accumulation was quantified by extracting Oil Red O using isopropanol and reading absorbance at $510 \mathrm{~nm}$. $n=3 \mathrm{biological}$ replicates. Data are presented as means \pm SD. Statistical comparison between groups was performed using Student's $t$-test. $\left.\left({ }^{*}\right) P<0.05\right)$. $(B)$ RNA-seq analysis at D7 of adipogenesis. The cutoff for differential expression is 2.5 -fold. (C) GO analysis of gene groups defined in $B$. $(D-F)$ MED1 is required for transcription of lipogenesis genes. $(D)$ Expression levels of representative genes are shown in RPKM values. $(E)$ Nascent RNA-seq analysis at D7 of adipogenesis. The cutoff for differential expression is twofold. (F) GO analysis of gene groups defined in $E .(G, H)$ Decreased Chrebp $\beta$ expression in Med1 KO brown adipocytes. (G) Profiles of nascent RNA-seq data around $C h r e b p$ locus. $(H)$ qRT-PCR of Chrebp $\alpha$ and Chrebp $\beta$ expression at D7 of adipogenesis. All qPCR data in cells are presented as means \pm SD. Two technical replicates from a single experiment were used. 
MED1 is required for lipogenesis but not early adipogenesis in culture

To understand how MED1 regulates lipogenesis, we established inducible $M e d 1 \mathrm{KO}\left(M e d 1^{\mathrm{f} / \mathrm{f}}\right.$; Cre-ER $)$ brown preadipocytes. Cells were treated with 4-hydroxytamoxifen (4OHT) to delete Med1, followed by the induction of adipogenesis. Consistent with the A-KO mouse phenotype, Med1 KO adipocytes showed a $>50 \%$ decrease in lipid content at day 7 (D7) of adipogenesis (Fig. 6A). RNA-seq analysis confirmed deletion of exons 8-10 of the Med1 gene (Supplemental Fig. S5A). MED1 is a subunit of general transcription coactivator complex Mediator. However, only about $1 \%$ of expressed genes were down-regulated in Med1 KO adipocytes at D7 (Fig. 6B). GO analysis showed that down-regulated genes were strongly functionally associated with fatty acid biosynthesis (Fig. 6C). Consistent with data obtained from mouse adipose tissues, deletion of $M e d 1$ led to decreases in expression of lipogenesis genes Acly, Acaca, Acacb, Fasn, Scd1, Gpam, and Agpat2 but not adipogenesis marker Pparg in immortalized and primary adipocytes differentiated in culture (Fig. 6D; Supplemental Figs. S5B, S6).

To better assess the role of MED1 in regulating lipogenesis gene transcription, we performed nascent RNA-seq analysis. Using a twofold cutoff, we found that only $\sim 2 \%$ of expressed genes were down-regulated transcriptionally in Med1 KO adipocytes at D7 (Fig. 6E). Consistent with steady-state RNA-seq data, nascent RNA-seq analysis indicated that deletion of Med1 reduces transcription levels of lipogenesis genes Acly, Acaca, Acacb, Fasn, Scd1, and Gpam but not adipogenesis markers Pparg and Cebpa (Fig. 6D-F). Interestingly, while Med1 KO did not affect the transcription of lipogenic TFs LXR $\alpha$, LXR $\beta$, and SREBP1, it specifically reduced transcription of the Chrebp $\beta$ isoform, which encodes a key lipogenic TF in adipocytes (Fig. 6G, H; Herman et al. 2012; Vijayakumar et al. 2017), suggesting that ChREBP may play a role in MED1-dependent lipogenesis. Together, these results suggest that MED1 is required for lipogenesis but not early adipogenesis in culture.

MED1 is required for Pol II binding on lipogenesis genes in adipocytes

To investigate whether MED1 affects chromatin accessibility and enhancer activation, we performed ATAC-seq (assay for transposase accessible chromatin with highthroughput sequencing) and ChIP-seq analyses of active enhancer mark H3K27ac, and RNA polymerase II (Pol II) at D7 of adipogenesis. On Med1 ${ }^{+}$promoters or enhancers in adipocytes, deletion of Med1 did not affect chromatin accessibility or H3K27ac levels (Fig. 7A,B). However, Med1 KO led to decreased binding of serine 5 phosphorylated (S5P) initiating Pol II, while having limited effects on serine 2 phosphorylated (S2P) elongating Pol II (Fig. 7A,B; Komarnitsky et al. 2000). GO analysis revealed that genes associated with MED1-dependent S5P-Pol II were strongly functionally associated with lipid metabolism including fatty acid biosynthesis (Fig. 7C). Consistent with nascent
RNA-seq data, deletion of Med1 clearly reduced both S5P-Pol II and S2P-Pol II binding on Scd1, Fasn, Agpat2, Acaca, and Gpam loci but not the Pparg locus (Fig. 7D,E; Supplemental Fig. S7). These data indicate that, while MED1 is dispensable for chromatin opening and enhancer activation, it is required for Pol II binding on lipogenesis genes in adipocytes.

\section{MED1 facilitates Mediator binding on ChREBP $P^{+}$ $S R E B P 1 a^{+}$lipogenic enhancers in adipocytes}

We hypothesized that MED1 regulates Pol II binding on lipogenesis genes by facilitating Mediator binding on lipogenic enhancers. To test this hypothesis, we first identified lipogenic enhancers that are bound by ChREBP or SREBP1a. Med $1{ }^{\mathrm{f} / \mathrm{f}}$;Cre-ER brown preadipocytes were infected with retroviruses expressing the triple $\mathrm{T} 7$ tagged constitutive active form of ChREBP (T7-CA-ChREBP) or the nuclear form of SREBP1a (T7-nSREBP1a) (Supplemental Fig. S8A). Cells were treated with 4OHT to delete Med1, followed by the induction of adipogenesis. We found that both ectopic ChREBP and SREBP1a failed to rescue the reduced lipogenesis in Med1 KO adipocytes (Fig. 8A,B). Next, we performed ChIP-seq using antibodies against T7 and MED12, which is a representative Mediator subunit (Kagey et al. 2010), at D7 of adipogenesis. Motif analysis of the T7-CA-ChREBP and T7-nSREBP1a binding regions identified the ChREBP and SREBP motifs as top motifs, respectively (Supplemental Fig. S8B). We identified active enhancers that are bound by ChREBP (2627) or SREBP1a (2183) (Supplemental Fig. S9A,E). The majority of these enhancers were bound by both ChREBP and SREBP1a (ChREBP ${ }^{+}$SREBP1a $\left.{ }^{+}, 1732\right)$. A subset of these lipogenic enhancers $\left(\right.$ ChREBP $^{+}, 934 / 2627$; SREBP1a ${ }^{+}$, 915/2183; and ChREBP ${ }^{+}$SREBP1a ${ }^{+}, 819 / 1732$ ) showed reduced MED12 binding in Med1 KO adipocytes (Fig. 8C; Supplemental Figs. S8C, S9B,C,F,G, ). Notably, lipid metabolism was a top GO term associated with genes that showed MED1-dependent MED12 binding (Fig. 8D; Supplemental Fig. S9D,H). Moreover, ChREBP- and SREBP1a-associated genes that show MED1-dependent MED12 binding exhibited reduced expression in Med1 KO cells (Fig. 8E), indicating that MED1 facilitates MED12 binding on ChREBP ${ }^{+}$SREBP $1 \mathrm{a}^{+}$lipogenic enhancers to regulate lipogenesis gene expression in adipocytes. Interestingly, ChREBP and SREBP1a directly bind to triglyceride synthesis genes Agpat2 and Gpam in addition to fatty acid synthesis enzyme genes Scd1, Fasn, Acaca, and Acly (Fig. 8F; Supplemental Fig. S10). Deletion of Med1 clearly reduced MED12 binding to lipogenesis genes Scd1, Fasn, Acaca, Acly, Agpat2, and Gpam loci but not the Pparg locus in adipocytes. Together with previous data, these results suggest that MED1 is a lipogenesis coactivator required for Mediator binding on $\mathrm{ChREBP}^{+}$ SREBP $1 \mathrm{a}^{+}$lipogenic enhancers in adipocytes (Fig. 8G).

\section{Discussion}

By crossing $M e d 1^{\mathrm{f} / \mathrm{f}}$ with Adipoq-Cre or Myf5-Cre mice, we selectively deleted Med1 in adipocytes or precursor 


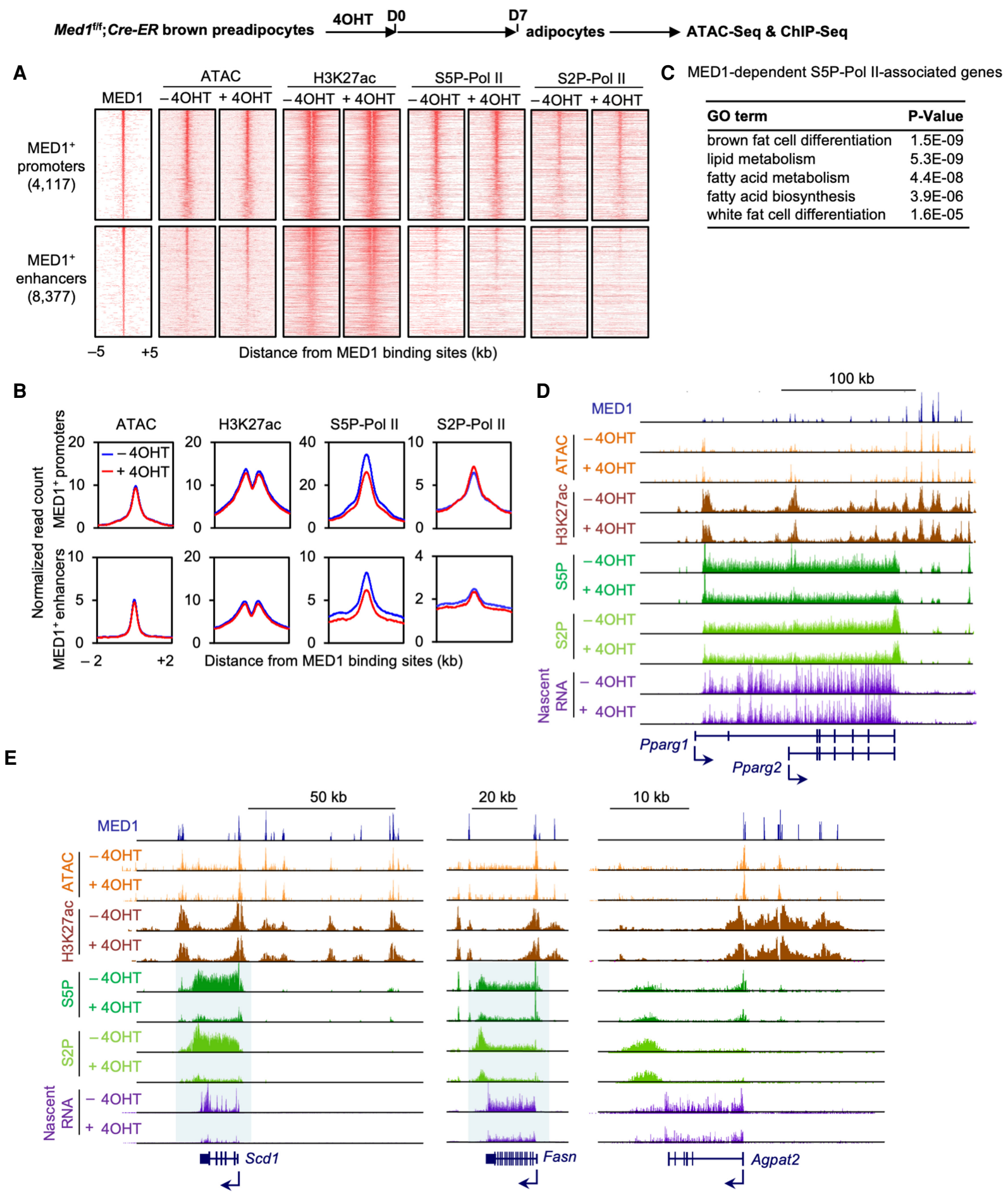

Figure 7. MED1 is required for Pol II binding on lipogenesis genes in adipocytes. Adipogenesis was done as in Figure 6. Cells were collected at D7 of adipogenesis for ATAC-seq and ChIP-seq of H3K27ac, S5P-Pol II, and S2P-Pol II. $(A, B)$ Med1 KO does not affect chromatin accessibility or enhancer activation but reduces S5P-Pol II binding on MED1 $1^{+}$promoters and enhancers in adipocytes. Heat maps $(A)$ and average profiles $(B)$ were aligned around the center of MED1 binding sites on MED1 ${ }^{+}$promoters (4117) and enhancers (8377). Published MED1 ChIP-seq data were used (GSE74189) (Lai et al. 2017). (C) GO analysis of genes associated with MED1-dependent S5P-Pol II. $(D, E)$ MED1 is required for Pol II binding on lipogenesis genes. Profiles of ATAC-seq, H3K27ac enrichment, S5P-Pol II, S2P-Pol II binding, and nascent RNA-seq data around Pparg, Scd1, Fasn, and Agpat2 gene loci are shown. Profiles around additional lipogenesis genes are shown in Supplemental Figure S7. 


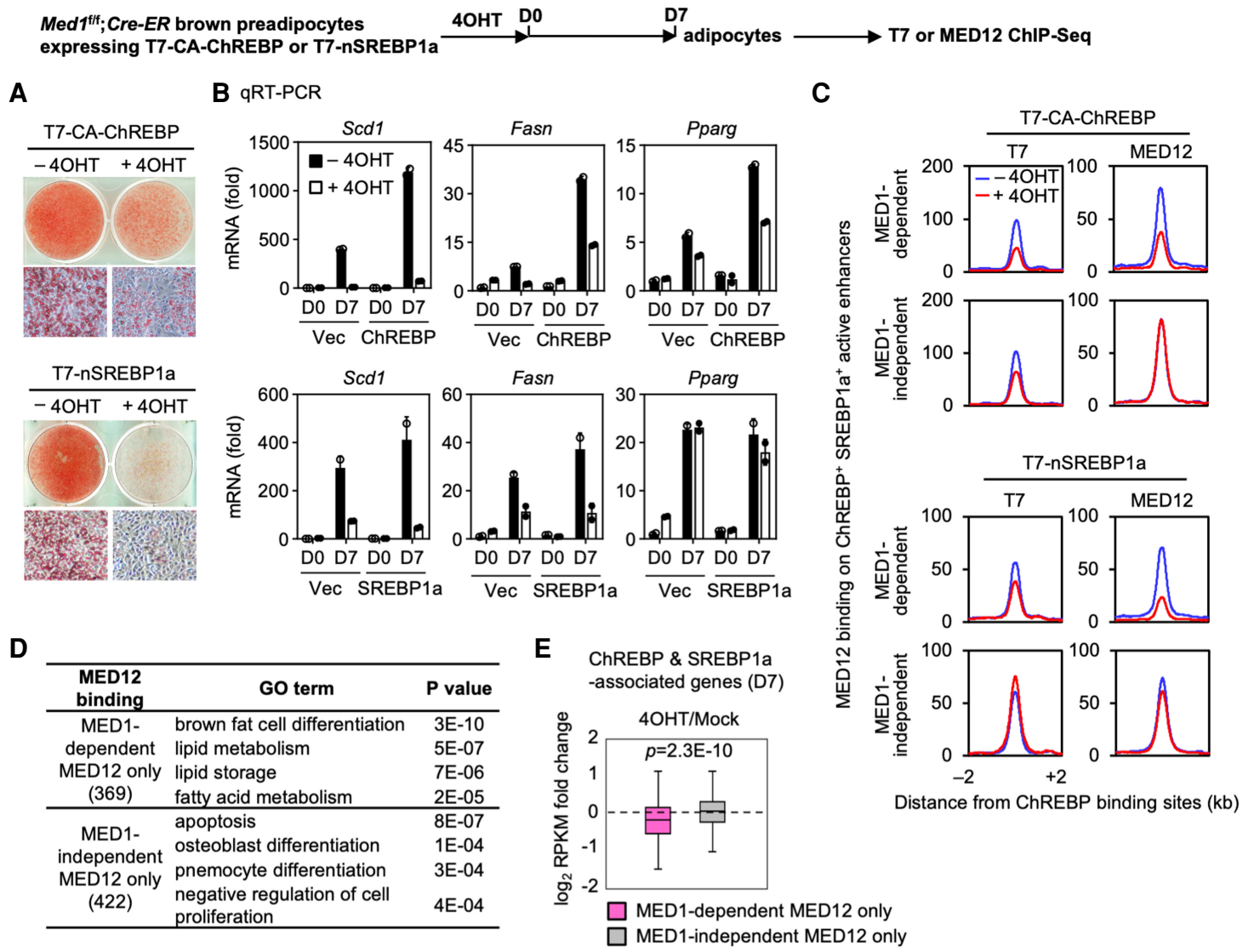

$\mathbf{F}$
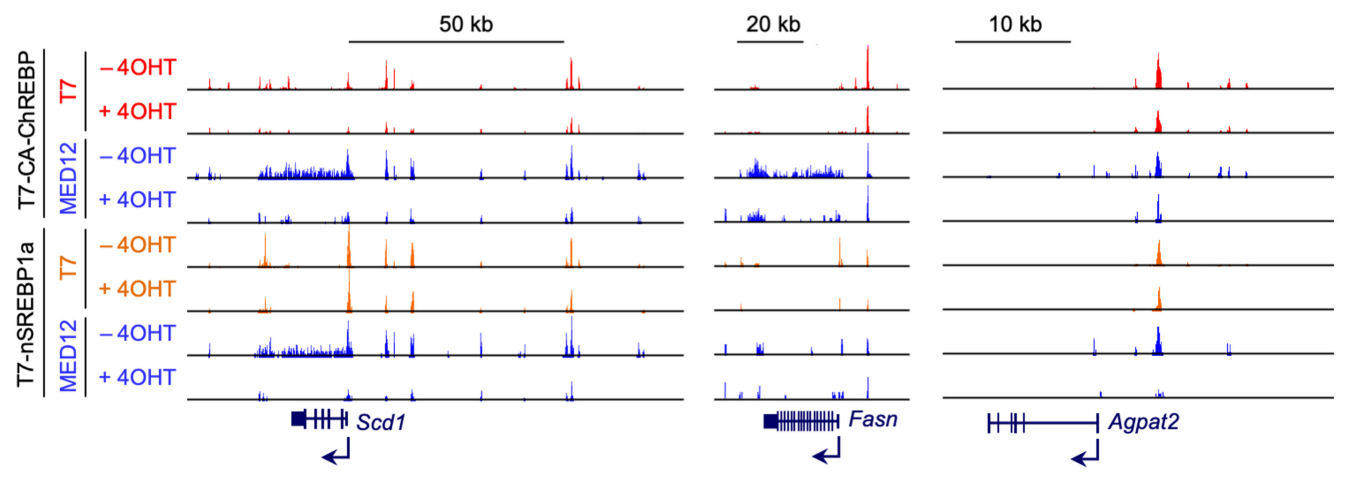

G

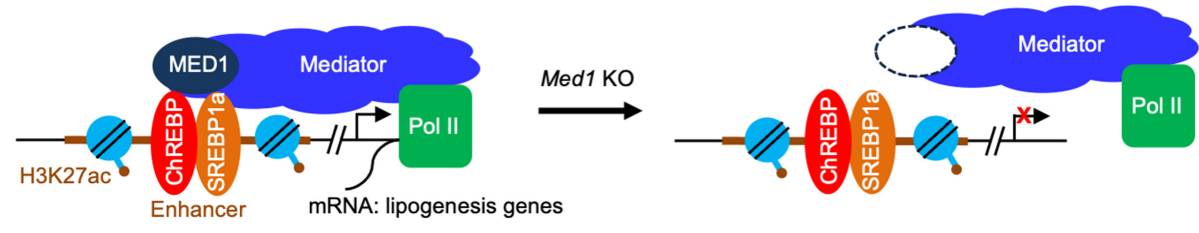

Figure 8. MED1 facilitates Mediator binding on ChREBP ${ }^{+}$SREBP1a ${ }^{+}$lipogenic enhancers in adipocytes. $(A, B)$ Ectopic CA-ChREBP or nSREBP1a fails to rescue reduced lipogenesis in Med1 KO. (A) Oil Red O staining at D7 of adipogenesis. (B) qRT-PCR of Scd1, Fasn, and Pparg expression. Two biological replicates were used. $(C, D)$ MED1 is required for MED12 binding on a subset of $C_{h R E B P}{ }^{+}$SREBP1a ${ }^{+}$ active enhancers. $(C)$ Average profiles around the center of T7-CA-ChREBP ${ }^{+}$active enhancers. $(D)$ GO analysis of genes that are associated with either MED1-dependent or MED1-independent MED12 binding on ChREBP ${ }^{+}$SREBP1a ${ }^{+}$active enhancers. $(E)$ MED1 facilitates MED12 binding to promote ChREBP- and SREBP1a-associated gene expression. Fold changes of RPKM values between control (Mock) and Med1 KO (4OHT) cells are shown in box plots. Statistical significance levels are indicated (Wilcoxon signed rank test, two-sided). $(F)$ MED1 is required for MED12 binding on lipogenesis genes. Profiles of T7-CA-ChREBP, T7-nSREBP1a, and MED12 binding on Scd1, Fasn, and Agpat2 gene loci are shown. $(G)$ Proposed model. 
cells in vivo. We found, surprisingly, that MED1 is required for postnatal adipose expansion but is largely dispensable for the development of adipose tissues. Consistently, MED1 is required for lipid accumulation but not early differentiation during adipogenesis in culture. Transcriptome analysis in mice and in culture indicates that only $2 \%-3 \%$ of expressed genes are down-regulated by $\mathrm{Med} 1 \mathrm{KO}$ in adipocytes. Down-regulated genes include key lipogenesis enzymes such as SCD1, FASN, and AGPAT2, but not early adipogenesis markers such as PPAR $\gamma$. Nascent RNA-seq in adipocytes reveals that Med1 KO specifically reduces transcription of the ChREBP $\beta$ isoform but not other lipogenic TFs. We further demonstrate that MED1 regulates Pol II binding on lipogenesis genes by promoting Mediator binding on $\mathrm{ChREBP}^{+}$ SREBP $1 \mathrm{a}^{+}$lipogenic enhancers in adipocytes. Together, our findings suggest that the MED1 subunit of the Mediator coactivator complex regulates postnatal adipose expansion by promoting lipogenesis gene expression.

By crossing Med1 ${ }^{\mathrm{f} / \mathrm{f}}$ with Myf5-Cre mice, we observed that Med1 KO had little effect on the size of embryonic BAT and the expression of adipogenesis markers such as PPAR $\gamma$ and C/EBPa. A-KO mice showed similar BAT and iWAT tissue masses and adipogenesis marker expression as the control mice at P10. In culture, deletion of Med1 in preadipocytes does not affect PPAR $\gamma$ or C/EBPa expression during differentiation of white and brown adipocytes. Together, these results indicate that MED1 is largely dispensable for the general development of adipose tissues. The requirement of MED1 for Ucp1 induction in BAT and iWAT is consistent with previous findings in cell culture that PRDM16 physically binds to and recruits MED1 to active enhancers of BAT-selective genes and that both PRDM16 and MED1 are required for Ucp1 induction in brown adipocytes (Harms et al. 2015; Iida et al. 2015). We also show that MED1 is largely dispensable for embryonic development of muscle. However, M$\mathrm{KO}$ mice show severe growth retardation and mortality around weaning age, suggesting that MED1 may play a role in muscle development and function after birth. These observations suggest that MED1 plays functional roles in late stages of adipogenesis and myogenesis rather than early stages of cell differentiation and tissue development.

Using adipocyte-specific transcriptome analysis, we show that postnatal adipose expansion is associated with marked induction of fatty acid synthesis enzymes (Fig. 4D-J). Transcriptome analyses at P10, $4 \mathrm{wk}$, and $8 \mathrm{wk}$ also reveal marked induction of fatty acid synthesis enzymes as well as lipogenic TF Chrebp in BAT and iWAT when mice switch from maternal milk to a carbohydratebased diet (Fig. 5F). These results explain previous observations that lipogenic enzyme activity and fatty acid synthesis in adipose tissues increase markedly after mice switch from breastfeeding to a carbohydrate-based diet (Pearce 1983). A-KO mice exhibit increasing lipodystrophy after weaning but not during the breastfeeding stage. A-KO mice also show severely impaired induction of fatty acid synthesis genes in BAT and iWAT when switching from high-fat maternal milk to a carbohy- drate-based diet. These data suggest that MED1 is required for carbohydrate-rich diet-induced postnatal adipose expansion and that lipodystrophy in A-KO mice is at least in part due to impaired induction of fatty acid synthesis genes. Consistently, Med1 KO reduces lipid accumulation and impairs the induction of fatty acid synthesis genes in adipocytes in culture.

We also observed impaired induction of Agpat2, Perilipin 1 (Plin1), Fatp1, and Fatp2 in adipose tissues of A-KO mice (Fig. 5F), which likely contributes to the observed lipodystrophy phenotype. AGPAT2 is a critical enzyme for triglyceride synthesis and is highly expressed in adipose tissues. Mutations of AGPAT2 lead to congenital generalized lipodystrophy in humans (Agarwal et al. 2002). Whole-body Agpat2 KO mice show a severe lipodystrophy phenotype similar to A-KO mice (Cortes et al. 2009). PLIN1 is an adipocyte-specific lipid-droplet coat protein that regulates fat storage and breakdown. Wholebody Plin1 KO mice show reduced adipose tissue mass (Martinez-Botas et al. 2000). Mutations of PLIN1 are associated with familial partial lipodystrophy in humans (Gandotra et al. 2011). A-KO mice show impaired induction of Agpat2 and Plin1 in BAT and iWAT from P10 to 4 wk (Fig. 5F). Med1 KO reduces Agpat2 expression in primary white and brown adipocytes in culture (Supplemental Fig. S6G). These results suggest that the impaired induction of Agpat2 and/or Plin1 likely contributes to the lipodystrophy in A-KO mice. Whole-body Fatp1 KO mice show reduced eWAT mass due to a significant reduction in adipocyte sizes (Wu et al. 2006). We cannot exclude the possibility that decreased expression of Fatp1/2 contributes to lipodystrophy in A-KO mice.

In Med 1 KO adipocytes, only $1 \%-2 \%$ of the $\sim 16,000$ expressed genes are down-regulated, indicating that MED1 is not generally required for transcription. Down-regulated genes are preferentially associated with lipogenesis, in particular fatty acid and triglyceride synthesis, such as Acaca, Elovl6, Fasn, Scd1, Agpat2, Gpam, and Chrebp $\beta$. ChREBP is a major transcriptional regulator of fatty acid synthesis in adipocytes. Vijayakumar et al. reported that Adipoq-Cre-mediated KO of Chrebp reduces the expression of lipogenesis genes including Acaca, Elov16, Fasn, and Scd1 in BAT and iWAT and significantly decreases perigonadal WAT mass (Vijayakumar et al. 2017). Chrebp KO led to a compensatory increase in Srebp1 expression in adipocytes, which could explain the mild lipodystrophy phenotype in these mice. SREBP1 is another critical transcriptional regulator for fatty acid synthesis in adipocytes (Horton et al. 2003). However, the whole-body KO of SREBP1 does not affect adiposity or DNL enzyme expression in WAT (Shimano et al. 1997). The fact that KO of either ChREBP or SREBP1 has mild or little effect on adipose tissue mass in mice suggests that ChREBP and SREBP1 have redundant functions in regulating lipogenesis gene expression in adipocytes. We show that MED1 is required for Mediator binding on $\mathrm{ChREBP}^{+}$and/or SREBP1 ${ }^{+}$lipogenic enhancers. ChREBP and SREBP1a directly bind to not only fatty acid synthesis genes Scd1, Fasn, Acaca, and Acly but also triglyceride synthesis genes Agpat2 and Gpam (Fig. 8F; Supplemental 
Fig. S10). Deletion of Med1 leads to reduced MED12 binding on a broad range of lipogenesis genes. Our findings suggest that MED1 is a master lipogenesis coactivator that cooperates with lipogenic TFs ChREBP and SREBP1a in adipocytes (Fig. 8G). Future work will be needed to simultaneously inactivate ChREBP and SREBP1 to determine whether these two TFs represent the major pathways by which MED1 regulates postnatal adipose expansion. Our current analysis uses a candidate approach and involves ChREBP and SREBP1. We cannot exclude the possibility that additional TFs require MED1 for activating lipogenesis genes in adipocytes.

Previous studies have implicated other Mediator subunits in SREBP1-dependent lipogenesis gene expression. A GST-fused SREBP1a activation domain can pull down the Mediator complex from cell nuclear extracts. SREBP1a directly interacts with MED15 (also called ARC105) in vitro. Depletion of MED15 down-regulates SREBPla-dependent FASN expression in human cells (Yang et al. 2006). CDK8 and Cyclin C, which associate with the transcriptionally inactive Mediator complex, have been reported as negative regulators of de novo lipogenesis in Drosophila and mice (Zhao et al. 2012). CDK8 and Cyclin $\mathrm{C}$ are dissociated from the Mediator complex upon refeeding with a carbohydrate-rich diet after fasting (Youn et al. 2019). Our finding that MED1 is a lipogenesis coactivator in adipocytes is consistent with these previous reports. Detailed molecular mechanisms by which Mediator regulates lipogenesis through its subunits including MED1, MED15, CDK8, and Cyclin C remain to be fully understood.

\section{Materials and methods}

Plasmids, antibodies, and chemicals

A triple T7 (3×T7) double StrepII tag was N-terminally subcloned into retroviral vector pMSCVhyg to generate pMSCVhyg-3xT7 using a pTAG1-hygroTK-N-term 3xT7 double StrepII tag (Brown et al. 2017) as a template. Constitutive active form of mouse ChREBP or nuclear form of mouse SREBPla was PCR-amplified using full-length clones as templates (Addgene 39235 and 32017) and was subcloned into pMSCVhyg-3xT7 to generate pMSCVhyg-3xT7-CA-ChREBP or pMSCVhyg-3xT7-nSREBP1a. All plasmids were confirmed by DNA sequencing. Anti-MED1 (A300-793A) and anti-MED12 (A300-774A) were from Bethyl Laboratories. Anti-FASN (no. 3810), anti-SCD1 (no. 2794), and anti-T7 (no. 132469) were from Cell Signaling Technology. Anti-C/EBP $\alpha$ (sc-61X) and anti-PPAR $\gamma$ (sc-7196X) were from Santa Cruz Biotechnology. Anti-H3K27ac (ab4729), anti-GFP (ab290), anti-S5P Pol II (ab5131), and anti-S2P Pol II (ab5095) were from Abcam. Anti- $\beta$-Actin (A1978) and (Z)-4-hydroxytamoxifen (4OHT) (H7904) were from Sigma.

\section{Generation of mouse strains}

Med $1^{\mathrm{f} / \mathrm{f}}$ mice (Jia et al. 2004) were crossed with Myf5-Cre (Jackson 007893), Adipoq-Cre (Jackson 028020), or Cre-ER (Jackson 008463 ) to generate $M e d 1^{\mathrm{f} / \mathrm{f}} ; M y f 5-C r e, M e d 1^{\mathrm{f} / \mathrm{f}} ;$ Adipoq-Cre, or $\operatorname{Med} 1{ }^{\mathrm{f} / \mathrm{f}}$;Cre-ER. For genotyping of Med1 alleles, PCR was performed using the following primers: 5'-TCTCCCCGGCTAA

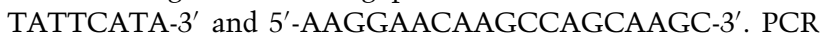

amplified $839 \mathrm{bp}$ from the wild-type and $575 \mathrm{bp}$ from the floxed allele. Rosa26 fSTRAP (TRAP) mice (Jackson 022367) (Zhou et al. 2013) were crossed with Adipoq-Cre (Jackson 028020) to generate TRAP;Adipoq-Cre mice. For genotyping of TRAP alleles, PCR was performed using the following primers: common forward, 5'-AAGGGAGCTGCAGTGGAGTA-3'; wild type reverse, 5'-CCGAAAATCTGTGGGAAGTC-3'; mutant reverse, 5'-CG GGCCATTTACCGTAAGTTAT-3'. PCR amplified 197 bp from the wild-type and $284 \mathrm{bp}$ from the TRAP allele. All mouse experiments were performed in accordance with the NIH Guide for the Care and Use of Laboratory Animals and approved by the Animal Care and Use Committee of the National Institute of Diabetes and Digestive and Kidney Diseases, National Institutes of Health.

\section{Translating ribosome affinity purification}

Brown and inguinal white adipose tissues from newborn (P0.5 for BAT or P2.5 for WAT) and adult (12 wk) TRAP;Adipoq-Cre mice were minced in homogenization buffer $(50 \mathrm{mM}$ Tris at $\mathrm{pH} 7.5$, $12 \mathrm{mM} \mathrm{MgCl}_{2}, 100 \mathrm{mM} \mathrm{KCl}, 1 \% \mathrm{NP}-40,100 \mathrm{mg} / \mathrm{mL}$ cycloheximide, $1 \mathrm{mg} / \mathrm{mL}$ sodium heparin, $2 \mathrm{mM}$ DTT, $0.2 \mathrm{U} / \mathrm{mL}$ RNasin, protease inhibitors) and homogenized by Dounce (Type B, $2 \mathrm{~mL}$ ). After incubation for $10 \mathrm{~min}$ on ice, lysates were centrifuged at $13,000 \mathrm{~g}$ for $10 \mathrm{~min}$ at $4^{\circ} \mathrm{C}$ and the supernatant was transferred to new tubes after removing the top lipid layer. The supernatant was incubated with anti-GFP antibody $(5 \mu \mathrm{g} / \mathrm{mL})$ prebound to Dynabeads Protein A (Invitrogen) for $2 \mathrm{~h}$ with endover-end rotation to capture the GFP-fused L10a subunit of the $60 \mathrm{~S}$ ribosome. Beads were collected on a magnetic rack and washed twice with low-salt wash buffer $(50 \mathrm{mM}$ Tris at $\mathrm{pH} 7.5$, $12 \mathrm{mM} \mathrm{MgCl} 2,100 \mathrm{mM} \mathrm{KCl}, 1 \% \mathrm{NP}-40,100 \mathrm{mg} / \mathrm{ml}$ cycloheximide, $2 \mathrm{mM} \mathrm{DTT})$ and then three times with high-salt wash buffer $(50 \mathrm{mM}$ Tris at $\mathrm{pH} 7.5,12 \mathrm{mM} \mathrm{MgCl} 2,300 \mathrm{mM} \mathrm{KCl}, 1 \%$ NP-40, $100 \mathrm{mg} / \mathrm{mL}$ cycloheximide, $2 \mathrm{mM}$ DTT). Immunoprecipitated ribosomes were immediately placed in the RLT buffer to extract RNA using the Qiagen Micro RNeasy kit (Qiagen) following the manufacturer's protocol.

\section{Metabolic studies}

For determination of serum metabolites, blood was collected from mice fed with standard laboratory mouse chow (15\% calories from fat, $56 \%$ calories from carbohydrate, $29 \%$ calories from protein; Envigo 7022 NIH-07) or high-fat diet (60\% calories from fat, $20 \%$ calories from carbohydrate, $20 \%$ calories from protein; Research Diets D12492). Serum was obtained by centrifuging blood samples at $12,000 \mathrm{~g}$ for $4 \mathrm{~min}$ at room temperature. Serum insulin and leptin concentrations were measured by an ELISA kit from CrystalChem and R\&D Systems, respectively. Serum free fatty acid, triglyceride, and cholesterol concentrations were measured with reagents from Roche Diagnostics $\mathrm{GmbH}_{\text {; }}$ Pointe Scientific, Inc.; and Thermo Scientific, respectively. For GTTs, mice were fasted overnight for $16 \mathrm{~h}$. For ITTs, mice were fasted for $4 \mathrm{~h}$. Mice received glucose $(1 \mathrm{~g} / \mathrm{kg}$ i.p. [intraperitoneally]), or human insulin (0.75 U/kg i.p.; Humulin, Eli Lilly), respectively, and blood was collected from the tail vein at specific time points. For both tests, blood glucose levels were determined using a portable glucometer (Contour Glucometer, Bayer). Serum concentrations of free fatty acid and glycerol were analyzed with reagents from Roche and Sigma, respectively. Food intake, $\mathrm{O}_{2}$ consumption, $\mathrm{CO}_{2}$ production, and locomotor activity were measured over 24 -h periods at $22^{\circ} \mathrm{C}$ and $29.5^{\circ} \mathrm{C}$ in a comprehensive laboratory animal monitor system (CLAMS) system (2.5-L chambers with plastic floors, using $0.6 \mathrm{~L} / \mathrm{min}$ flow rate, one mouse per chamber; Columbus Instruments, Inc.) after a 48-h adaptation 
period. For the cold tolerance test, mice were individually housed at room temperature $\left(22^{\circ} \mathrm{C}\right)$ and then in a cold room $\left(6^{\circ} \mathrm{C}\right)$ for $6 \mathrm{~h}(\mathrm{n}$ $=6$ per group). Core body temperature was measured using a rectal thermometer (TH-5; Braintree Scientific) before and hourly after cold exposure. Body composition was measured with the EchoMRI 3-in-1 analyzer (Echo Medical Systems). CL316,243 $\left(0.1 \mathrm{mg} \mathrm{kg}{ }^{-1}\right.$; Sigma-Aldrich) or saline were administered intraperitoneally and $\mathrm{O}_{2}$ consumption was measured at $30^{\circ} \mathrm{C}$ from 1 to $4 \mathrm{~h}$ after injection. For in vivo lipolysis, blood was collected 20 min after the injection of CL316,243 or saline. In mice fed with HFD, energy expenditure was calculated by the energy balance technique (Ravussin et al. 2013; Zhuang et al. 2018).

Primary preadipocytes culture, immortalization, and adipogenesis

Primary brown preadipocytes were isolated from interscapular BAT of newborn Med1 ${ }^{\mathrm{f} / \mathrm{f}}$;Cre-ER pups and immortalized by infecting retroviruses expressing SV40T. Immortalized cells were further infected with retroviruses expressing 3xT7-CA-ChREBP or the $3 \times \mathrm{xT} 7$ vector. Primary white adipocytes were from inguinal WAT of $M e d 1^{\mathrm{f} / \mathrm{f}} ;$ Adipoq-Cre or Med1 ${ }^{\mathrm{f} / \mathrm{f}}$ adult mice. For the adipogenesis assay, preadipocytes were plated in growth medium (DMEM plus $10 \%$ FBS) 3-4 d before the induction and were induced with $0.02 \mu \mathrm{M}$ insulin, $1 \mathrm{nM}$ T3, $0.5 \mathrm{mM}$ IBMX, $2 \mu \mathrm{g}$ $\mathrm{mL}^{-1} \mathrm{DEX}$, and $0.125 \mathrm{mM}$ indomethacin for $2 \mathrm{~d}$. For adipogenesis of primary white preadipocytes, $1 \mu \mathrm{M}$ rosiglitazone was included throughout the differentiation (Park and Ge 2017; Park et al. 2017).

Western blot and $q R T-P C R$

Western blot of nuclear extracts or whole-tissue lysates was done as described (Jang et al. 2019). Total RNA was extracted using TRIzol (Invitrogen) and reverse-transcribed using a ProtoScript II first strand cDNA synthesis kit (NEB), following the manufacturers' protocols. qRT-PCR of Med1 exon 8 was performed using SYBR green primers: forward 5'-CCTGTTTGATGGGATGTCCA-3', and reverse, 5'-GCAGAGATATGCAGATTGCC-3'. Chrep $\alpha$ and Chrebp $\beta$ qRT-PCR primers were described previously (Herman et al. 2012). SYBR green primers for other genes were described previously (Jin et al. 2011; Park and Ge 2017).

\section{RNA-seq library preparation}

Total RNA ( $1 \mu \mathrm{g}$ ) or TRAP-isolated RNA (200 ng) was subjected to the NEBNext poly(A) mRNA magnetic isolation module (NEB) to isolate mRNA and proceeded directly to double-stranded cDNA synthesis. Library construction was done using the NEBNext Ultra II RNA library preparation kit for Illumina (NEB) following the manufacturer's protocol.

\section{Nascent RNA-seq library preparation}

Cells $\left(10^{6}\right)$ were labeled with $0.5 \mathrm{mM}$ ethylene uridine for $30 \mathrm{~min}$ at $37^{\circ} \mathrm{C}$. After RNA extraction, $1 \mu \mathrm{g}$ of total RNA was depleted of rRNA using the NEBNext rRNA depletion kit (NEB). To capture nascent RNA, the sample was biotinylated by the Click-iT nascent RNA capture kit (Thermo Fisher C10365) according to the manufacturer's instructions. Double-stranded cDNAs were synthesized using a SuperScript double-stranded cDNA synthesis kit (Invitrogen). Library construction was done using a NEBNext Ultra II DNA library preparation kit for Illumina (NEB) according to the manufacturer's instructions. Sequencing libraries were analyzed with Qubit and pooled and sequenced on a HiSeq3000.
ChIP-seq and ATAC-seq library preparation

ChIP-seq was performed as described in detail previously (Lee et al. 2013, 2017; Lai et al. 2017; Zhuang et al. 2018). ChIP-seq of $\mathrm{T} 7$ and MED12 were done in the presence of Drosophila spike-in chromatin and antibody following the manufacturers' protocol (Active Motif). ChIP-seq library construction was done using a NEBNext Ultra II DNA library preparation kit for Illumina (NEB) following the manufacturer's protocol. For ATACseq, 50,000 cells were washed with PBS and collected in a cold lysis buffer $\left(10 \mathrm{mM}\right.$ Tris- $\mathrm{HCl}$ at $\mathrm{pH} 7.4,10 \mathrm{mM} \mathrm{NaCl}, 3 \mathrm{mM} \mathrm{MgCl}{ }_{2}$, $0.1 \%$ Igepal CA-630). After lysis, the nuclear pellet was resuspended in the transposase reaction mix (Illumina, Nextera Tn5 transposase kit) and incubated for $30 \mathrm{~min}$ at $37^{\circ} \mathrm{C}$. Immediately following transposition, the sample was purified by a Qiagen MinElute kit (Qiagen). Eluted DNA was amplified with PCR using Nextera i7 and i5 index primers (Illumina) and purified with AMPure XP magnetic beads (Beckman Coulter). Sequencing libraries were analyzed with Qubit and pooled and sequenced on a HiSeq2500 or HiSeq3000.

\section{Computational analysis}

RNA-seq data analysis Raw sequencing data were aligned to the mouse $\mathrm{mm} 9$ genome using STAR software (Dobin et al. 2013). Reads on exonic regions or gene bodies (nascent RNA-seq) were collected to calculate reads per kilobase per million (RPKM) as a measure of gene expression level. Only genes with RPKM $>1$ were considered expressed. Gene ontology $(\mathrm{GO})$ analysis of differentially expressed genes was carried out using DAVID bioinformatics resources (https://david.ncifcrf.gov).

ChIP-seq peak calling and GO analysis of genomic regions Raw sequencing data were aligned to the mouse $\mathrm{mm} 9$ genome using bowtie2. To identify ChIP-enriched regions, we used the "SICER" method (Zang et al. 2009). For H3K27ac enrichment, the window size of $200 \mathrm{bp}$ and the estimated false discovery rate (FDR) threshold of $10^{-10}$ were used. For ChIP-seq of S5P-Pol II, S2P-Pol II, T7, and MED12, the window size of $50 \mathrm{bp}$ and the FDR threshold of $10^{-3}$ were used. Previously published MED1 ChIP-seq data were used (GSE74189). GO analysis of genomic regions was done using GREAT (http://great.stanford.edu/public/html).

Motif analysis For motif analysis of 3xT7-CA-ChREBP or 3xT7nSREBP1a binding sites, we used the SeqPos motif tool in Galaxy Cistrome (http://cistrome.org/ap/root) with default parameters. We selected the top 3000 binding regions to screen enriched TF motifs based on the FDR value provided by SICER.

Normalization of ChIP-seq data For ChIP-seq spike-in normalization, sequences were aligned to the Drosophila genome dm6. Normalization factors were determined by counting Drosophila tags and applying to mouse tags to generate normalized heat maps and profiles (Fig. 8; Supplemental Fig. S8).

Heat maps and box plots Heat map matrices were generated using in-house scripts with 50-bp resolution and visualized in $\mathrm{R}$ using gplots package. The ratio of RPKM values in Med1 KO and control cells in base 2 logarithm was plotted using box plot, with outliers not shown (Fig. 8). A Wilcoxon signed rank test (two-sided) was used to determine statistical differences.

ATAC-seq data analysis Raw sequencing reads were processed using Kundaje laboratory's ataqc pipelines (https://github.com/ kundajelab/atac_dnase_pipelines). For downstream analysis, we 
used filtered reads that remained after removing unmapped reads, duplicates, and mitochondrial reads.

Data availability

RNA-seq, ATAC-seq, and ChIP-seq data sets generated in the paper have been deposited in NCBI Gene Expression Omnibus under accession number GSE160605.

\section{Competing interest statement}

The authors declare no competing interests.

\section{Acknowledgments}

We thank Janardan K. Reddy for kindly providing Med1-flox mice, Aaron Broun and David Wu for technical assistance in genotyping, Yinyan Ma from the National Institute of Diabetes and Digestive and Kidney Diseases (NIDDK) Mouse Metabolism Core for technical assistance with metabolic studies, Rob Klose for the $3 \times \mathrm{xT} 7$ tag plasmid, the NIDDK Genomics Core and National Heart, Lung, and Blood Institute DNA Sequencing and Genomics Core for next-generation sequencing, and Susanna Maisto for proofreading the manuscript. This work was supported by the Intramural Research Program of NIDDK, National Institutes of Health to K.G.

Author contributions: Y.J. and K.G. conceived the study. Y.J., Y.-K.P., J.-E.L., and O.G. performed the methodology. Y.J., Y.-K.P., J.-E.L., D.W., O.G., N.T., and K.G. performed the investigation. J.-E.L., Y.J., and Y.-K.P. were responsible for the software and performed the formal analysis and data curation. Y.J., J.-E.L., and K.G. wrote the original draft of the manuscript. Y.J., J.-E.L., Y.-K.P., N.T., and K.G. reviewed and edited the manuscript. K.G. administered the project and acquired the funding.

\section{References}

Abdul-Wahed A, Guilmeau S, Postic C. 2017. Sweet sixteenth for ChREBP: established roles and future goals. Cell Metab 26: 324-341. doi:10.1016/j.cmet.2017.07.004

Agarwal AK, Arioglu E, De Almeida S, Akkoc N, Taylor SI, Bowcock AM, Barnes RI, Garg A. 2002. AGPAT2 is mutated in congenital generalized lipodystrophy linked to chromosome 9q34. Nat Genet 31: 21-23. doi:10.1038/ng880

Allen BL, Taatjes DJ. 2015. The Mediator complex: a central integrator of transcription. Nat Rev Mol Cell Biol 16: 155-166. doi:10.1038/nrm3951

Berry DC, Stenesen D, Zeve D, Graff JM. 2013. The developmental origins of adipose tissue. Development 140: 3939-3949. doi:10.1242/dev.080549

Brown DA, Di Cerbo V, Feldmann A, Ahn J, Ito S, Blackledge NP, Nakayama M, McClellan M, Dimitrova E, Turberfield AH, et al. 2017. The SET1 complex selects actively transcribed target genes via multivalent interaction with CpG island chromatin. Cell Rep 20: 2313-2327. doi:10.1016/j.celrep.2017.08.030

Cortes VA, Curtis DE, Sukumaran S, Shao X, Parameswara V, Rashid S, Smith AR, Ren J, Esser V, Hammer RE, et al. 2009. Molecular mechanisms of hepatic steatosis and insulin resistance in the AGPAT2-deficient mouse model of congenital generalized lipodystrophy. Cell Metab 9: 165-176. doi:10.1016/j.cmet .2009 .01 .002
Cristancho AG, Lazar MA. 2011. Forming functional fat: a growing understanding of adipocyte differentiation. Nat Rev Mol Cell Biol 12: 722-734. doi:10.1038/nrm3198

Dobin A, Davis CA, Schlesinger F, Drenkow J, Zaleski C, Jha S, Batut P, Chaisson M, Gingeras TR. 2013. STAR: ultrafast universal RNA-seq aligner. Bioinformatics 29: 15-21. doi:10 $.1093 /$ bioinformatics/bts635

Eguchi J, Wang X, Yu S, Kershaw EE, Chiu PC, Dushay J, Estall JL, Klein U, Maratos-Flier E, Rosen ED. 2011. Transcriptional control of adipose lipid handling by IRF4. Cell Metab 13: 249-259. doi:10.1016/j.cmet.2011.02.005

Gandotra S, Le Dour C, Bottomley W, Cervera P, Giral P, Reznik Y, Charpentier G, Auclair M, Delepine M, Barroso I, et al. 2011. Perilipin deficiency and autosomal dominant partial lipodystrophy. $N$ Engl I Med 364: 740-748. doi:10.1056/ NEJMoal007487

Ge K, Guermah M, Yuan CX, Ito M, Wallberg AE, Spiegelman BM, Roeder RG. 2002. Transcription coactivator TRAP220 is required for PPAR $\gamma 2$-stimulated adipogenesis. Nature 417: 563-567. doi:10.1038/417563a

Ge K, Cho YW, Guo H, Hong TB, Guermah M, Ito M, Yu H, Kalkum M, Roeder RG. 2008. Alternative mechanisms by which mediator subunit MED1/TRAP220 regulates peroxisome proliferator-activated receptor $\gamma$-stimulated adipogenesis and target gene expression. Mol Cell Biol 28: 1081-1091. doi:10 .1128/MCB.00967-07

Harms MJ, Lim HW, Ho Y, Shapira SN, Ishibashi J, Rajakumari S, Steger DJ, Lazar MA, Won KJ, Seale P. 2015. PRDM16 binds MED1 and controls chromatin architecture to determine a brown fat transcriptional program. Genes Dev 29: 298-307. doi:10.1101/gad.252734.114

Herman MA, Peroni OD, Villoria J, Schön MR, Abumrad NA, Blüher M, Klein S, Kahn BB. 2012. A novel ChREBP isoform in adipose tissue regulates systemic glucose metabolism. $\mathrm{Na}$ ture 484: 333-338. doi:10.1038/nature10986

Horton JD, Shimomura I, Ikemoto S, Bashmakov Y, Hammer RE. 2003. Overexpression of sterol regulatory element-binding protein-1a in mouse adipose tissue produces adipocyte hypertrophy, increased fatty acid secretion, and fatty liver. $J$ Biol Chem 278: 36652-36660. doi:10.1074/jbc.M306540200

Iida S, Chen W, Nakadai T, Ohkuma Y, Roeder RG. 2015. PRDM16 enhances nuclear receptor-dependent transcription of the brown fat-specific Ucp1 gene through interactions with Mediator subunit MED1. Genes Dev 29: 308-321. doi:10.1101/gad.252809.114

Ito M, Yuan CX, Okano HJ, Darnell RB, Roeder RG. 2000. Involvement of the TRAP220 component of the TRAP/SMCC coactivator complex in embryonic development and thyroid hormone action. Mol Cell 5: 683-693. doi:10.1016/S10972765(00)80247-6

Jang Y, Broun A, Wang C, Park YK, Zhuang L, Lee JE, Froimchuk E, Liu C, Ge K. 2019. H3.3K4M destabilizes enhancer H3K4 methyltransferases MLL3/MLL4 and impairs adipose tissue development. Nucleic Acids Res 47: 607-620. doi:10.1093/ nar/gky982

Jia Y, Qi C, Kashireddi P, Surapureddi S, Zhu YJ, Rao MS, Le Roith D, Chambon P, Gonzalez FJ, Reddy JK. 2004. Transcription coactivator $\mathrm{PBP}$, the peroxisome proliferator-activated receptor (PPAR)-binding protein, is required for PPARa-regulated gene expression in liver. I Biol Chem 279: 24427-24434. doi:10.1074/jbc.M402391200

Jin Q, Yu LR, Wang L, Zhang Z, Kasper LH, Lee JE, Wang C, Brindle PK, Dent SY, Ge K. 2011. Distinct roles of GCN5/PCAFmediated $\mathrm{H} 3 \mathrm{~K} 9 \mathrm{ac}$ and $\mathrm{CBP} / \mathrm{p} 300$-mediated $\mathrm{H} 3 \mathrm{~K} 18 / 27 \mathrm{ac}$ in 
nuclear receptor transactivation. EMBO J 30: 249-262. doi:10 .1038/emboj.2010.318

Kagey MH, Newman JJ, Bilodeau S, Zhan Y, Orlando DA, van Berkum NL, Ebmeier CC, Goossens J, Rahl PB, Levine SS, et al. 2010. Mediator and cohesin connect gene expression and chromatin architecture. Nature 467: 430-435. doi:10.1038/ nature 09380

Komarnitsky P, Cho EJ, Buratowski S. 2000. Different phosphorylated forms of RNA polymerase II and associated mRNA processing factors during transcription. Genes Dev 14: 24522460. doi:10.1101/gad.824700

Lai B, Lee JE, Jang Y, Wang L, Peng W, Ge K. 2017. MLL3/MLL4 are required for $\mathrm{CBP} / \mathrm{p} 300$ binding on enhancers and super-enhancer formation in brown adipogenesis. Nucleic Acids Res 45: 6388-6403. doi:10.1093/nar/gkx234

Lee JE, Wang C, Xu S, Cho YW, Wang L, Feng X, Baldridge A, Sartorelli V, Zhuang L, Peng W, et al. 2013. H3k4 mono- and dimethyltransferase MLL4 is required for enhancer activation during cell differentiation. Elife 2: e01503. doi:10.7554/eLife.01503

Lee JE, Park YK, Park S, Jang Y, Waring N, Dey A, Ozato K, Lai B, Peng W, Ge K. 2017. Brd4 binds to active enhancers to control cell identity gene induction in adipogenesis and myogenesis. Nat Commun 8: 2217. doi:10.1038/s41467-017-02403-5

Lefterova MI, Zhang Y, Steger DJ, Schupp M, Schug J, Cristancho A, Feng D, Zhuo D, Stoeckert CJ, Liu XS, et al. 2008. PPAR $\gamma$ and C/EBP factors orchestrate adipocyte biology via adjacent binding on a genome-wide scale. Genes Dev 22: 2941-2952. doi:10.1101/gad.1709008

Malik S, Roeder RG. 2010. The metazoan Mediator co-activator complex as an integrative hub for transcriptional regulation. Nat Rev Genet 11: 761-772. doi:10.1038/nrg2901

Martinez-Botas J, Anderson JB, Tessier D, Lapillonne A, Chang $\mathrm{BH}$, Quast MJ, Gorenstein D, Chen KH, Chan L. 2000. Absence of perilipin results in leanness and reverses obesity in Lepr $^{d b / d b}$ mice. Nat Genet 26: 474-479. doi:10.1038/82630

Nuotio-Antar AM, Poungvarin N, Li M, Schupp M, Mohammad M, Gerard S, Zou F, Chan L. 2015. FABP4-Cre mediated expression of constitutively active ChREBP protects against obesity, fatty liver, and insulin resistance. Endocrinology 156: 4020-4032. doi:10.1210/en.2015-1210

Park YK, Ge K. 2017. Glucocorticoid receptor accelerates, but is dispensable for, adipogenesis. Mol Cell Biol 37: e00260-16. doi:10.1128/MCB.00260-16

Park YK, Wang L, Giampietro A, Lai B, Lee JE, Ge K. 2017. Distinct roles of transcription factors KLF4, Krox20, and peroxisome proliferator-activated receptor $\gamma$ in adipogenesis. Mol Cell Biol 37: e00554-16. doi:10.1128/MCB.00554-16

Pearce J. 1983. Fatty acid synthesis in liver and adipose tissue. Proc Nutr Soc 42: 263-271. doi:10.1079/PNS19830031

Poungvarin N, Chang B, Imamura M, Chen J, Moolsuwan K, SaeLee C, Li W, Chan L. 2015. Genome-wide analysis of ChREBP binding sites on male mouse liver and white adipose chromatin. Endocrinology 156: 1982-1994. doi:10.1210/en.2014-1666

Ravussin Y, Gutman R, LeDuc CA, Leibel RL. 2013. Estimating energy expenditure in mice using an energy balance technique. Int J Obes 37: 399-403. doi:10.1038/ijo.2012.105

Rosen ED, Hsu CH, Wang X, Sakai S, Freeman MW, Gonzalez FJ, Spiegelman BM. 2002. C/EBPa induces adipogenesis through PPAR : a unified pathway. Genes Dev 16: 22-26. doi:10.1101/ gad.948702

Schmidt SF, Jørgensen M, Chen Y, Nielsen R, Sandelin A, Mandrup S. 2011. Cross species comparison of C/EBPa and PPAR $\gamma$ profiles in mouse and human adipocytes reveals interdependent retention of binding sites. BMC Genomics 12: 152. doi:10.1186/1471-2164-12-152
Shimano H, Shimomura I, Hammer RE, Herz J, Goldstein JL, Brown MS, Horton JD. 1997. Elevated levels of SREBP-2 and cholesterol synthesis in livers of mice homozygous for a targeted disruption of the SREBP-1 gene. I Clin Invest 100: 2115-2124. doi:10.1172/JCI119746

Song Z, Xiaoli AM, Yang F. 2018. Regulation and metabolic significance of de novo lipogenesis in adipose tissues. Nutrients 10: 1383. doi:10.3390/nu10101383

Strable MS, Ntambi JM. 2010. Genetic control of de novo lipogenesis: role in diet-induced obesity. Crit Rev Biochem Mol Biol 45: 199-214. doi:10.3109/10409231003667500

Takeuchi K, Reue K. 2009. Biochemistry, physiology, and genetics of GPAT, AGPAT, and lipin enzymes in triglyceride synthesis. Am J Physiol Endocrinol Metab 296: E1195-E1209. doi:10.1152/ajpendo.90958.2008

Tallquist MD, Weismann KE, Hellstrom M, Soriano P. 2000. Early myotome specification regulates PDGFA expression and axial skeleton development. Development 127: 5059-5070.

Vijayakumar A, Aryal P, Wen J, Syed I, Vazirani RP, MoraesVieira PM, Camporez JP, Gallop MR, Perry RJ, Peroni OD, et al. 2017. Absence of carbohydrate response element binding protein in adipocytes causes systemic insulin resistance and impairs glucose transport. Cell Rep 21: 1021-1035. doi:10 .1016/j.celrep.2017.09.091

Whyte WA, Orlando DA, Hnisz D, Abraham BJ, Lin CY, Kagey MH, Rahl PB, Lee TI, Young RA. 2013. Master transcription factors and Mediator establish super-enhancers at key cell identity genes. Cell 153: 307-319. doi:10.1016/j.cell.2013.03.035

Wu Q, Ortegon AM, Tsang B, Doege H, Feingold KR, Stahl A. 2006. FATP1 is an insulin-sensitive fatty acid transporter involved in diet-induced obesity. Mol Cell Biol 26: 3455-3467. doi:10.1128/MCB.26.9.3455-3467.2006

Yang F, Vought BW, Satterlee JS, Walker AK, Jim Sun ZY, Watts JL, DeBeaumont R, Saito RM, Hyberts SG, Yang S, et al. 2006. An ARC/Mediator subunit required for SREBP control of cholesterol and lipid homeostasis. Nature 442: 700-704. doi:10 $.1038 /$ nature04942

Youn DY, Xiaoli AM, Kwon H, Yang F, Pessin JE. 2019. The subunit assembly state of the Mediator complex is nutrient-regulated and is dysregulated in a genetic model of insulin resistance and obesity. I Biol Chem 294: 9076-9083. doi:10 $.1074 /$ jbc.RA119.007850

Zang C, Schones DE, Zeng C, Cui K, Zhao K, Peng W. 2009. A clustering approach for identification of enriched domains from histone modification ChIP-seq data. Bioinformatics 25: 1952-1958. doi:10.1093/bioinformatics/btp340

Zhao X, Feng D, Wang Q, Abdulla A, Xie XJ, Zhou J, Sun Y, Yang ES, Liu LP, Vaitheesvaran B, et al. 2012. Regulation of lipogenesis by cyclin-dependent kinase 8-mediated control of SREBP1. J Clin Invest 122: 2417-2427. doi:10.1172/JCI61462

Zhou P, Zhang Y, Ma Q, Gu F, Day DS, He A, Zhou B, Li J, Stevens SM, Romo D, et al. 2013. Interrogating translational efficiency and lineage-specific transcriptomes using ribosome affinity purification. Proc Natl Acad Sci 110: 15395-15400. doi:10 $.1073 /$ pnas. 1304124110

Zhu Y, Qi C, Jia Y, Nye JS, Rao MS, Reddy JK. 2000. Deletion of $\mathrm{PBP} / \mathrm{PPARBP}$, the gene for nuclear receptor coactivator peroxisome proliferator-activated receptor-binding protein, results in embryonic lethality. I Biol Chem 275: 14779-14782. doi:10.1074/jbc.C000121200

Zhuang L, Jang Y, Park YK, Lee JE, Jain S, Froimchuk E, Broun A, Liu C, Gavrilova O, Ge K. 2018. Depletion of Nsd2-mediated histone H3K36 methylation impairs adipose tissue development and function. Nat Commun 9: 1796. doi:10.1038/ s41467-018-04127-6 


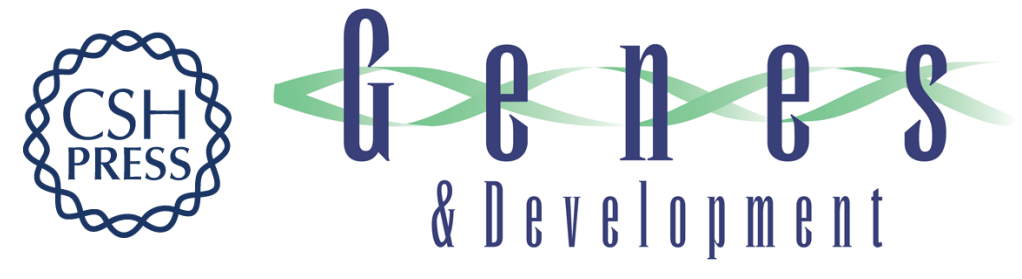

\section{MED1 is a lipogenesis coactivator required for postnatal adipose expansion}

Younghoon Jang, Young-Kwon Park, Ji-Eun Lee, et al.

Genes Dev. 2021, 35: originally published online April 22, 2021

Access the most recent version at doi:10.1101/gad.347583.120

\section{Supplemental http://genesdev.cshlp.org/content/suppl/2021/04/21/gad.347583.120.DC1 Material}

Related Content

Critical roles of transcriptional coactivator MED1 in the formation and function of mouse adipose tissues

Keiichi Ito, Marc Schneeberger, Alan Gerber, et al.

Genes Dev. May , 2021 35: 729-748

References This article cites 51 articles, 16 of which can be accessed free at:

http://genesdev.cshlp.org/content/35/9-10/713.full.html\#ref-list-1

Articles cited in:

http://genesdev.cshlp.org/content/35/9-10/713.full.html\#related-urls

License This is a work of the US Government.

Email Alerting
Service $\begin{aligned} & \text { Receive free email alerts when new articles cite this article - sign up in the box at the top } \\ & \text { right corner of the article or click here. }\end{aligned}$

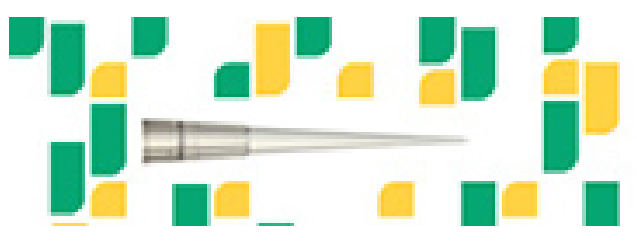

Focused on your science. 